\title{
Identification of Neurotensin Receptor Expressing Cells in the Ventral Tegmental Area across the Lifespan
}

\author{
DHillary L. Woodworth, ${ }^{1}$ - Patricia A. Perez-Bonilla, ${ }^{2}$ Bethany G. Beekly, ${ }^{1}$ - Trevor J. Lewis, ${ }^{1}$ and ${ }^{\circledR}$ Gina \\ M. Leinninger ${ }^{1}$
}

DOI:http://dx.doi.org/10.1523/ENEURO.0191-17.2018

${ }^{1}$ Department of Physiology, Michigan State University, East Lansing, MI 48824 and ${ }^{2}$ Neuroscience Program and Department of Pharmacology and Toxicology, Michigan State University, East Lansing, MI 48824

\begin{abstract}
Neurotensin (Nts) promotes activation of dopamine (DA) neurons in the ventral tegmental area (VTA) via incompletely understood mechanisms. Nts can signal via the G protein-coupled Nts receptors 1 and 2 (NtsR1 and NtsR2), but the lack of methods to detect NtsR1- and NtsR2-expressing cells has limited mechanistic understanding of Nts action. To overcome this challenge, we generated dual recombinase mice that express FlpO-dependent Cre recombinase in NtsR1 or NtsR2 cells. This strategy permitted temporal control over recombination, such that we could identify NtsR1or NtsR2-expressing cells and determine whether their distributions differed between the developing and adult brain. Using this system, we found that NtsR1 is transiently expressed in nearly all DA neurons and in many non-DA neurons in the VTA during development. However, NtsR1 expression is more restricted within the adult brain, where only two thirds of VTA DA neurons expressed NtsR1. By contrast, NtsR2 expression remains constant throughout lifespan, but it is predominantly expressed within glia. Anterograde tract tracing revealed that NtsR1 is expressed by mesolimbic, not mesocortical DA neurons, suggesting that VTA NtsR1 neurons may represent a functionally unique subset of VTA DA neurons. Collectively, this work reveals a cellular mechanism by which Nts can directly engage NtsR1-expressing DA neurons to modify DA signaling. Going forward, the dual recombinase strategy developed here will be useful to selectively modulate NtsR1- and NtsR2-expressing cells and to parse their contributions to Nts-mediated behaviors.
\end{abstract}

Key words: brain; developmental; dopamine; dual recombinase; glia; mesolimbic

\section{Significance Statement}

The activation of ventral tegmental area (VTA) dopamine (DA) neurons is disrupted in many neuropsychiatric diseases. The neuropeptide neurotensin (Nts) activates DA neurons by incompletely understood receptor mechanisms, which may be useful to modify aberrant VTA DA signaling in disease states. Using new mouse models, this study demonstrates that Nts receptor subtypes are differentially expressed in the VTA. In particular, one Nts receptor subtype is expressed predominantly on VTA DA neurons, while glial cells express a different receptor subtype. Thus, this work reveals the cellular mechanism by which Nts directly acts on DA neurons and may guide development of Nts-mediated therapies to improve DA signaling in neuropsychiatric diseases.

Received May 30, 2017; accepted January 25, 2018; First published January 31, 2018.

The authors declare no competing financial interests.

Author contributions: H.L.W. and G.M.L. designed research; H.L.W., P.A.P.B., B.G.B., and T.J.L. performed research; H.L.W., P.A.P.-B., B.G.B., and T.J.L. analyzed data; H.L.W. and G.M.L. wrote the paper.
This work was supported by National Institute of Diabetes and Digestive and Kidney Diseases Grants F30-DK107163 (to H.L.W.) and R01-DK103808 (to G.M.L.). P.A.P.-B. is supported by the National Institutes of Health-funded Integrative Pharmacological Science Training Program (2T32-GM092715-06). Acknowledgements: We thank the transgenic cores at University of Michigan and Van Andel Research Institute for assistance generating NtsR1 Neo-Cre 


\section{Introduction}

The neuropeptide, neurotensin (Nts), is expressed throughout the central nervous system and has been linked to numerous physiologic and behavioral processes including feeding, body temperature, nociception, emotional state, and sleep (Bissette et al., 1982; Remaury et al., 2002; Fitzpatrick et al., 2012; Kleczkowska and Lipkowski, 2013; Boules et al., 2014; Woodworth et al., 2017 b). While the precise neural circuits by which Nts acts to modify behavior remain undetermined, it is well-established that Nts modulates dopamine (DA) transmission. Nts signaling may therefore be a target of interest for the treatment of diseases linked with altered DA signaling, including Parkinson's disease, schizophrenia, drug addiction, and obesity (Cáceda et al., 2006; Boules et al., 2014).

Nts signals via the $\mathrm{G}$ protein-coupled Nts receptors 1 and 2 (NtsR1 and NtsR2), which are both expressed in the brain and have been implicated in Nts-mediated behaviors (Tanaka et al., 1990; Vita et al., 1993; Chalon et al., 1996; Mazella et al., 1996). Nts also binds the intracellular receptor, NtsR3/sortilin, which may regulate recycling and sorting of Nts (Mazella et al., 1998; Kleczkowska and Lipkowski, 2013). Studies using pharmacological antagonists and mice null for NtsR1 or NtsR2 suggest that each receptor isoform mediates distinct aspects of physiology, and hence that they may be expressed on different cell types (Schroeder and Leinninger, 2017). The lack of methods to detect and manipulate NtsR1- or NtsR2-expressing cells, however, has limited understanding of the cellular mechanisms by which Nts regulates behavior. In situ hybridization (ISH) and autoradiography methods to detect Ntsr1 indicate that it is expressed robustly within the ventral tegmental area (VTA) of adult animals (Nicot et al., 1994; Alexander and Leeman, 1998; Lein et al., 2007). Similar techniques reveal diffuse expression of Ntsr2 throughout the brain that may be within both neurons and glia (Nouel et al., 1997; Sarret et al., 1998; Walker et al., 1998; Sarret et al., 2003). Interestingly, the expression patterns of NtsR1 and NtsR2 in the brain may also vary with age. For example, Ntsr1 is transiently upregulated during gestation and peaks shortly after birth, but is subsequently downregulated as animals reach maturity, with high levels persisting in the VTA (Palacios et al., 1988). By contrast, Ntsr2 expression is initially low and gradually increases with age (Sarret et al., 1998; LépéeLorgeoux et al., 1999). Taken together, these data indicate that Ntsr1 and Ntsr2 have distinct expression patterns that vary across the lifespan, and may be found on different cell types within the nervous system.

and NtsR2 ${ }^{\text {Neo-Cre }}$ mice. Martin G. Myers (University of Michigan) kindly provided the Ad-Syn-mCherry virus. David P. Olson graciously shared the Creinducible Rosa ${ }^{\text {eGFP-L10a }}$ reporter line used in these studies.

Correspondence should be addressed to Gina M. Leinninger, Ph.D., Department of Physiology, Michigan State University, 567 Wilson Road, BPS Building, Room 3183, East Lansing, MI 48824, E-mail: leinning@msu.edu.

DOI:http://dx.doi.org/10.1523/ENEURO.0191-17.2018

Copyright (C) 2018 Woodworth et al.

This is an open-access article distributed under the terms of the Creative Commons Attribution 4.0 International license, which permits unrestricted use, distribution and reproduction in any medium provided that the original work is properly attributed.
The differences in Ntsr1 and Ntsr2 expression suggest that each isoform may regulate distinct aspects of developmental and adult physiology. Indeed, previous work demonstrates that central Nts promotes DA release, locomotor activity, hypothermia, anorexia, and reward via NtsR1 (Pettibone et al., 2002; Remaury et al., 2002; Leonetti et al., 2004; Kim et al., 2008; Kempadoo et al., 2013; Opland et al., 2013; Rouibi et al., 2015), whereas NtsR2 may confer the pain-reducing effects of Nts (Remaury et al., 2002; Maeno et al., 2004; Roussy et al., 2010; Kleczkowska and Lipkowski, 2013). However, the evidence for distinct roles of NtsR1 and NtsR2 is not entirely consistent and has been complicated by methodological limitations. For example, the commonly used NtsR1-selective antagonist SR48692 also acts as an agonist at NtsR2 (Botto et al., 1997; Vita et al., 1998; Yamada et al., 1998), while a potential compound to selectively antagonize NtsR2 has only recently been developed (Thomas et al., 2016). NtsR1 and NtsR2 knockout mice have also been used to examine the specific roles of each receptor, but developmental deletion in these models may lead to compensatory changes that mask normal action of the Nts system. (Pettibone et al., 2002; Remaury et al., 2002; Kim et al., 2008; Liang et al., 2010). Thus, while NtsR-selective pharmacologic agents and knock-out models have added to understanding of central Nts action, developing methods to visualize and manipulate select NtsR1 or NtsR2 populations in vivo is essential to deciphering the neural circuits and physiology regulated by each receptor.

To address this challenge, we developed dual recombinase knock-in mouse models in which FlpO is required to induce IRES-Cre in cells that express NtsR1 or NtsR2. Cre-mediated recombination can be used to induce reporter or effector proteins in these cells to permit their detection, and indeed Cre-driver lines have proven to be reliable reagents to identify genetically specified cell populations (Krashes et al., 2011; Leinninger et al., 2011; Vong et al., 2011). As NtsR1 and NtsR2 expression varies with age (Palacios et al., 1988; Lépée-Lorgeoux et al., 1999), we engineered FlpO-dependent Cre expression in NtsR1 and NtsR2 cells, allowing for temporal control over recombination by inducing $\mathrm{FlpO}$ expression at defined time points (either embryogenesis or adulthood). Given the well-established description of Nts as a modulator of DA signaling, but the lack of understanding of which VTA cells mediate it, we used these mice to define the cellular distribution of NtsR1 and NtsR2 within the VTA.

\section{Materials and Methods}

\section{Generation of NtsR1 $1^{N E O-C r e}$ and NtsR2 $2^{\text {NEO-Cre }}$ knock -in mice}

We have tested commercial antibodies against NtsR1 or NtsR2, but they did not yield labeling consistent with the ISH distribution of NtsR1 and NtsR2 in mouse brain (Lein et al., 2007), or sufficient to discern which cells express these receptor isoforms. (Antibodies tried for NtsR1 include Santa Cruz sc-374492 and aNeuromics GP14020. Antibodies tried for NtsR2 were Santa Cruz sc-67011 and Neuromics RA17100). We therefore gener- 
ated knock-in mice to permit facile identification of NtsR1- and NtsR2-expressing cells. NtsR $1^{\text {NEO-Cre }}$ and $N$ tsR2 ${ }^{N E O-C r e}$ targeting vectors were generated by inserting an IRES-Cre between the stop codon and the polyadenylation site of the sequence encoding the 3' end of the mouse NtsR1 gene, with an frt-flanked NEO cassette placed upstream of the IRES-Cre. The linearized targeting vector was electroporated into mouse R1 embryonic stem (ES) cells (129sv background) and cells were selected with G418. DNA from ES cell clones was analyzed via qPCR for loss of homozygosity using Taqman primer and probes for the genomic NtsR1 or NtsR2 insertion sites (NtsR1: forward, TCTGATGTTGGACTTGGGTTC; reverse, TCTGATGTTGGACTTGGGTTC; probe, TCTGATGTTGGACTTGGGTTC and NtsR2: forward, ACCCATCAGATAAGCCATGC; reverse, GTGGGAAGTTGAGGGCAG; probe, GTCTAAGCGGACCTACTGACCCA). NGF was used as a copy number control (Soliman et al., 2007). Putative positive ES clones were expanded, confirmed for homologous recombination by Southern blot and injected into mouse C57BL/6 blastocysts to generate chimeras. Chimeric males were mated with C57BL/6 females (The Jackson Laboratory), and germline transmission was determined initially via progeny coat color, then confirmed via conventional PCR for IRES-Cre.

\section{Breeding and genotyping}

Mice were bred and housed in a 12/12 h light/dark cycle with ad libitum access to water and food (Harlan Teklad \#7913). All procedures were approved by the Institutional Animal Care and Use Committee at Michigan State University in accordance with Association for Assessment and Accreditation of Laboratory Animal Care and National Institutes of Health guidelines. Heterozygous $N t s R 1^{N E O-C r e}$ and Nts $R 2^{N E O-C r e}$ mice were bred either to FlpO deleter mice (Jax Stock \#012930), a Creinducible Rosa ${ }^{\text {eGFP-L10a }}$ reporter (Krashes et al., 2014) that was graciously provided to us by David P. Olson (University of Michigan), or to C57/BI6 wild-type mice to maintain the lines.

\section{Developmental model}

NtsR $1^{\text {NEO-Cre }}$ and NtsR2 $2^{N E O-C r e}$ mice were bred to a FIpO deleter line and progeny that inherited the FlpO allele (NtsR $1^{\Delta N E O-C r e}$ and NtsR2 ${ }^{\triangle N E O-C r e}$ ) were subsequently mated with a Cre-inducible Rosa ${ }^{\text {eGFP-L10a }}$ reporter, generating $N t s R 1^{D e v}$;GFP and $N$ tsR $2^{D e v}$;GFP mice. Progeny that were heterozygous for both IRES-Cre and GFP alleles were used for analysis.

Adult model

NtsR $1^{N E O-C r e}$ and NtsR2NEO-Cre mice were mated directly to Cre-inducible Rosa ${ }^{\text {eGFP-L10a }}$ animals, producing heterozygous NtsR $1^{N E O-C r e} ; G F P$ and NtsR2 $2^{N E O-C r e} ; G F P$ progeny. These animals were then injected with FlpO adenovirus in adulthood (see below) to generate $N$ ts $R 1^{\text {Adult }}$; GFP and NtsR2 $2^{\text {Adult; }}$ GFP study mice. All animals were genotyped by standard PCR using the following primer sequences. IRES-Cre: forward, GGACGTGGTITTCCTITGAA and reverse, AGGCAAATTITGGTGTACGG. Rosa26 EGFP-L10a: mutant forward, TCTACAAATGTGGTAGATCCAGGC; wild type forward, GAGGGGAGTGTTGCAATACC; common, CAGAT-
GACTACCTATCCTCCC. FlpO: mutant, GCGAAGAGTाGTCCTCAACC; common, GCG AAG AGT TTG TCC TCA ACC; wild type, GGAGCGGGAGAAATGGATATG. Adult male and female mice of each model were studied.

\section{Surgery}

Adult NtsR $1^{\text {Adult }}$;GFP and NtsR2 $2^{\text {Adult }}$;GFP mice received a presurgical injection of carprofen $(5 \mathrm{mg} / \mathrm{kg}$, s.c.) and were anesthetized with $3-4 \%$ isoflurane $/ \mathrm{O}_{2}$ in an induction chamber before being placed in a stereotaxic frame (Kopf). Under 1-2\% isoflurane, access holes were drilled in the skull allowing a guide cannula with stylet (Plastics One) to be lowered into the lateral ventricles (A/P: -0.22 , $\mathrm{M} / \mathrm{L}: \pm 1.0, \mathrm{D} / \mathrm{V}:-2.0)$. Mice were bilaterally injected with 1 $\mu$ FlpO adenovirus (Vector Biolabs), which was infused at a rate of $1 \mu \mathrm{l} / \mathrm{min}$. The animals recovered for $10 \mathrm{~d}$ before perfusion to permit sufficient time for FlpO-mediated excision of the frt-flanked NEO cassette and GFP expression. For tracing studies, NtsR ${ }^{\Delta N E O-C r e ; G F P ~ m i c e ~ w e r e ~}$ injected unilaterally in the VTA (A/P: $-3.2, \mathrm{M} / \mathrm{L}$ : \pm 0.48 , D/V: -4.65) with 75-100 nl of Ad-syn-mCherry, an adenovirus expressing a Cre-dependent synaptophysin-mCherry fusion protein (Opland et al., 2013). Mice recovered for either 7-10 d or four weeks after surgery to allow for Cre-mediated recombination and synaptophysinmCherry expression at presynaptic terminals. The Ad-SynmCherry tracing system has been validated previously, including verification of its Cre dependence to induce synaptophysin-mCherry expression (Woodworth et al., 2017a).

\section{Perfusion and immunofluorescence}

Mice were treated with a lethal dose of intraperitoneal pentobarbital followed by transcardial perfusion with $10 \%$ neutral-buffered formalin (Fisher Scientific). Brains were removed, postfixed in $10 \%$ formalin overnight at $4^{\circ} \mathrm{C}$ and dehydrated with $30 \%$ sucrose in PBS for 2-3 d. Then, each brain was sectioned into four series of $30-\mu \mathrm{m}$ coronal sections, each of which provides a representative survey of the entire brain. For experiments, a single series of brain sections from each mouse was analyzed by immunofluorescence or immunohistochemistry as previously described (Leinninger et al., 2011; Opland et al., 2013). For characterization of NtsR1-GFP and NtsR2-GFP cells, sections were exposed to chicken anti-GFP (1:2000, Abcam, catalog \#ab13970 RRID: AB_300798), S100 $\beta$ (1:1000, Abcam, catalog \#ab52642, RRID: AB_88246), NeuN (1:1000, MilliporeSigma, catalog \#MAB377, RRID: AB_2298772), and mouse anti-TH (1:1000, Millipore, catalog \#MAB318 RRID: AB_2201528), followed by incubation with species-specific secondary antibodies conjugated to Alexa Fluor 488 or 568 fluorophores (Life Technologies catalog \#A10037 RRID: AB_2534013 and Jackson ImmunoResearch catalog \#703-545-155 RRID: AB_2340375). Brains were analyzed using an Olympus BX53 fluorescence microscope outfitted with FITC and Texas Red filters. Microscope images were collected using Cell Sens software and a Qi-Click 12 Bit cooled camera, and images were analyzed using Photoshop software (Adobe). Masks were applied to images to enhance bright- 
ness and/or contrast in Photoshop, and in every case, the mask was applied uniformly to the entire image.

\section{Cell counts}

Brains were sectioned into four series of $30-\mu \mathrm{m}$ coronal sections, each of which provides a representative survey of the entire brain. Only one series of the four was directly analyzed in counting studies to determine the number of neurons in the VTA. We then multiplied the number of counted neurons by four to estimate the total number of neurons in the entire VTA. For each mouse, multiple $10 \times$ images were captured of each VTA-containing brain section and were assigned a bregma coordinate based on the atlas of Paxinos and Franklin (Paxinos and Franklin, 2001). We chose $10 \times$ magnification because an entire VTA hemisphere can be captured in a single $10 \times$ image, which allowed us to identify multiple landmarks within the image used to define the borders of the VTA. $10 \times$ images spanning the entire rostro-caudal axis of the VTA (roughly bregma -3.90 to $-3.00 \mathrm{~mm}$ ) were then compiled using Photoshop, so that images from each animal were arranged side-by-side according to bregma level. The Paxinos atlas and cellular architecture was used to identify the midline and interpeduncular nucleus (ip) that comprise the medial boundary of the VTA, and the sites of the medial lemniscus $(\mathrm{ml})$, and substantia nigra $(\mathrm{SN})$ were used to determine the lateral border of the VTA. Where possible, $\mathrm{TH}$ immunoreactivity was used to define the superior and inferior borders of the VTA, as well as to dissociate TH neurons of the VTA and SN (as the TH+ neurons in the SN tend to be smaller and more tightly packed compared to those of the VTA). Together, these criteria were used to draw the borders of the VTA onto each image. Once the VTA boundaries were defined, five representative VTA sections spanning bregma -3.90 to $-3.00 \mathrm{~mm}$ were selected from each mouse, and were used to quantify GFP or GFP/TH+ neurons. Sections were $\sim 0.15-0.20 \mathrm{~mm}$ apart from each other to maintain equal coverage of the VTA between mice. Images chosen for counting were digitally magnified in Photoshop to $20 \times$ or higher, so that the experimenter could easily identify and count the number of GFP or GFP/TH+ double-positive neurons. For GFP counts: Nts $R 1^{\text {Dev }} n=3, N t s R 2^{D e v} n=3, N t s R 1^{\text {Adult }}$ $n=3, N$ tsR2 $2^{\text {Adult }} n=6$. To determine the percentage of all VTA $\mathrm{TH}+$ neurons that colocalize with NtsR1-GFP or NtsR2-GFP: NtsR $1^{\text {Dev }} n=3 ; N t s R 2^{D e v} n=3 ; N t s R 1^{\text {Adult }}$ $n=3 ; N$ tsR2 $2^{\text {Adult }} n=6$.

\section{Statistics}

All data were analyzed in Prism 6 (GraphPad) using unpaired $t$ tests. Bar graphs represent mean \pm SEM. See Table 1 for power analysis.

\section{Results}

\section{Dual recombinase strategy to label NtsR1- and NtsR2-expressing cells}

To identify NtsR1 or NtsR2 cells "on command," we generated knock-in mouse models that express Cre in NtsR1 or NtsR2 cells only after FlpO-mediated recombination. To do this, we inserted an frt-flanked NEO cas-
Table 1. Statistical table

\begin{tabular}{llll}
\hline Figure & Data structure & Statistical test & Power \\
a Fig. $2 G$ & Normal distribution & Unpaired $t$ test & 1.00 \\
b Fig. $2 H$ & Normal distribution & Unpaired $t$ test & 1.00 \\
c Fig. $5 E$ & Normal distribution & Unpaired $t$ test & 0.99 \\
d Fig. $5 F$ & Normal distribution & Unpaired $t$ test & 1.00 \\
e Fig. $5 G$ & Normal distribution & Unpaired $t$ test & 1.00 \\
f Fig. $5 H$ & Normal distribution & Unpaired $t$ test & 1.00 \\
\hline
\end{tabular}

sette upstream of an IRES-Cre sequence and cloned it into the non-coding region of the NtsR1 or NtsR2 genomic sequences; we refer to these as Nts $R 1^{N E O-C r e}$ and NtsR2 $2^{N E O-C r e}$ mice (Fig. 1). The frt-flanked NEO cassette blocks Cre expression unless $N E O$ is removed, thus $N t s R 1^{N E O-C r e}$ and $N t s R 2^{N E O-C r e}$ mice lack Cre expression until exposure to FlpO.

To reveal cells that express NtsR1 and NtsR2 during development, we crossed NtsR $1^{N E O-C r e}$ and NtsR2 $2^{N E O-C r e}$ mice to a FlpO deleter line, producing progeny that lack the frt-flanked NEO cassette and thus produce Cre whenever Ntsr1 or Ntsr2 is transcribed throughout the lifespan (NtsR $1^{\Delta N E O-C r e}$ and NtsR2 $2^{\triangle N E O-C r e}$ mice). The NtsR $1^{\triangle N E O-C r e}$ and NtsR2 $2^{\triangle N E O-C r e}$ mice were subsequently bred to a Cre-inducible Rosa ${ }^{\text {eGFP-L10a }}$ reporter line; in progeny heterozygous for each allele, any cell that expresses NtsR1 or NtsR2 will undergo Cremediated recombination to express GFP. Notably, the recombination is permanent, so GFP labeling persists even in cells that cease to express Ntsr1 or Ntsr2. This model enables us to visualize any cells that expressed Ntsr1 or Ntsr2 from conception onward, and we refer to these as $N$ ts $R 1^{D e v}$;GFP and $N$ ts $R 2^{D e v}$; GFP mice (Fig. 1A).

To study the adult expression pattern of Ntsr1 and $N t s r 2$, we bred NtsR $1^{N E O-C r e}$ and NtsR2 $2^{N E O-C r e}$ mice to the Cre-inducible Rosa ${ }^{\text {GFP-L10a }}$ reporter. In this case, the progeny (NtsR $1^{N E O-C r e} ; G F P$ and NtsR2 $2^{N E O-C r e} ;$ GFP mice) carry the GFP allele, but no reporter is expressed because the frt-flanked NEO cassette suppresses Cre expression. These mice were maintained in our colony until they reached adulthood, then they were injected with an adenovirus expressing FlpO recombinase (AdFlpO) into the lateral ventricles to permit viral spread and vector expression throughout the adult brain (Ghodsi et al., 1999; Gholizadeh et al., 2013). The subsequently expressed FlpO excises the frt-flanked NEO, which permits Cre-mediated GFP expression only in cells that actively express Ntsr1 or Ntsr2, allowing us to visualize the adult expression patterns of these receptor subtypes (NtsR1 $1^{\text {Adult }}$;GFP and NtsR2 $2^{\text {Adult }}$;GFP mice; Fig. 1B).

\section{Distribution and morphology of NtsR1 and NtsR2 in the VTA}

We first examined the mouse lines used for these studies to verify their Cre-dependent regulation of GFP expression. This is vital, because any nonspecific GFP expression could lead to over interpretation of the distribution and/or number of NtsR1- or NtsR2-expressing 
A

\section{Breed NtsR1Neo-Cre Mice to FlpO Deleter Line}

2. Mate NtsR1 ${ }^{1 \mathrm{Neo}-\mathrm{Cre}}$ mice to Cre-Inducible GFP Reporter

\section{Breed NtsR1 ${ }^{\text {Neo-Cre }}$ mice to Cre-inducible GFP line}

\section{Inject adult progeny with Ad-FIpO to induce Cre expression}

Generation of NtsR1 ${ }^{\text {Dev }}$;GFP Mice

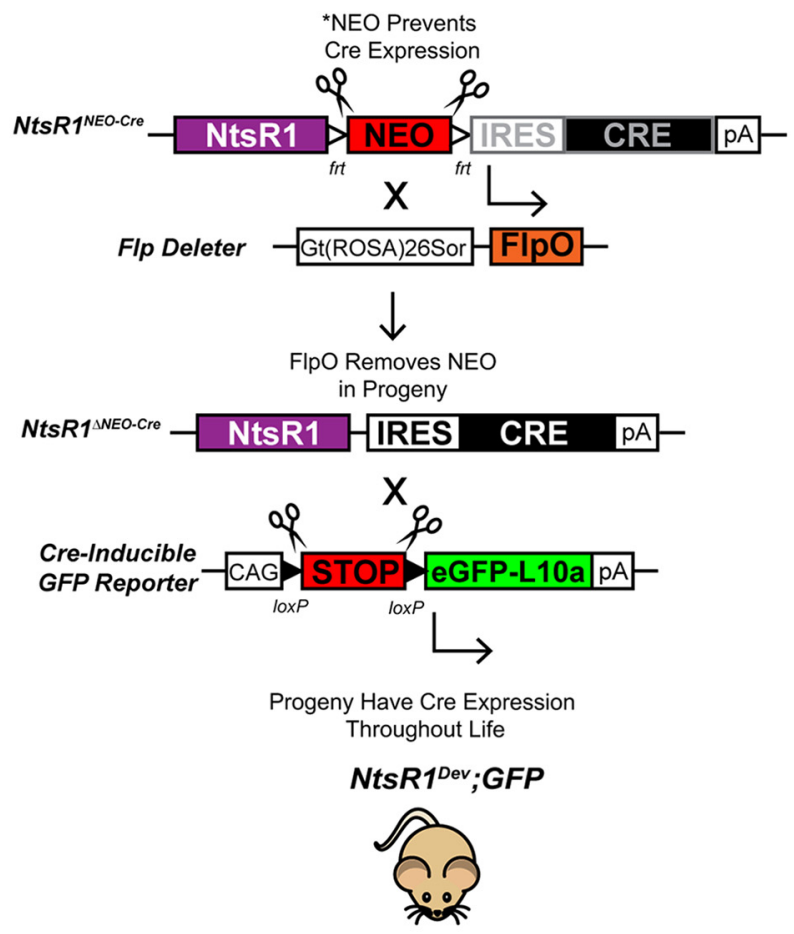

\section{Generation of NtsR1 ${ }^{\text {Adult }}$;GFP Mice}
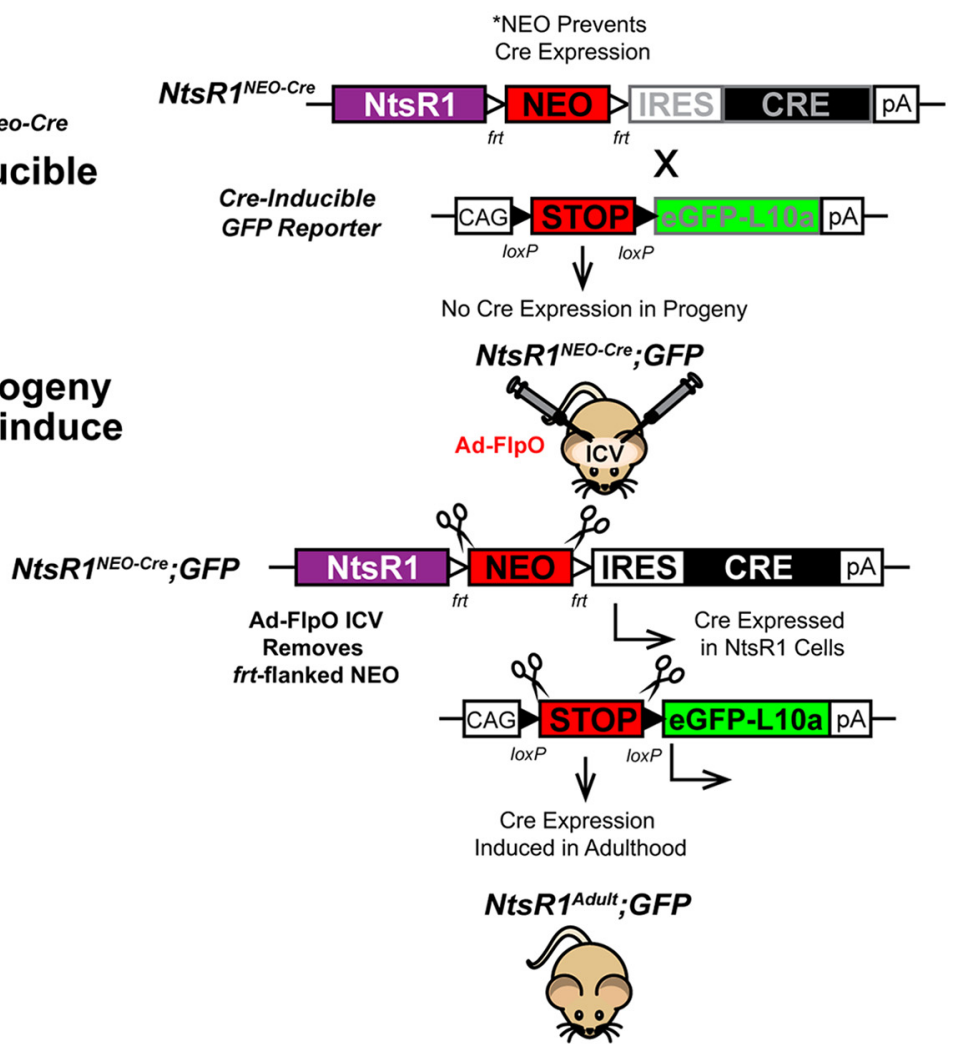

Figure 1. Generation of mouse models to identify developmental versus adult expression patterns of NtsR1 and NtsR2. $\boldsymbol{A}$, Schematic demonstrating how constitutive Cre expression is induced in $N t s R 1^{N e o-C r e}$ mice, resulting in GFP labeling of any neuron that expresses NtsR1 throughout the lifespan (NtsR1 ${ }^{\text {Dev }}$ model). B, Schematic depiction of how Cre expression is suppressed until 
continued

adulthood in NtsR $1^{\text {Neo-Cre }}$ mice, resulting in GFP labeling restricted to cells actively expressing NtsR1 in adult animals (NtsR1 ${ }^{\text {Adult }}$ model). The same strategies depicted in $\boldsymbol{A}, \boldsymbol{B}$ were used in $N$ ts $R 2^{N e o-C r e}$ mice.

cells in the brain, and obscure subsequent analyses. As a first step, we assessed any potential "leakiness" of the Rosa ${ }^{\text {eGFP-L10a }}$ reporter line, and whether its GFP expression is specifically Cre dependent. Indeed, we found that Rosa ${ }^{\text {eGFP-L10a }}$ reporter mice lacking Cre $(++$;GFP mice) do not exhibit GFP expression in the VTA or anywhere in the brain, even after injected with Ad-FlpO to permit expression of the FlpO recombinase (Fig. 2A); thus, Cre recombinase is necessary to drive GFP expression in this line. Next, we assessed any potential leakiness in NEOCre containing mice crossed onto the Rosa $a^{\text {eGFP-L10a }}$ reporter line, which are the basis of the "Adult" models for identifying mature NtsR1- or NtsR2-expressing cells. Per our design (Aim 1B), we predicted that the frt-flanked NEO cassette should effectively block Cre expression and thus Cre-mediated GFP expression. Indeed we found no GFP expression in the VTA or anywhere in the brain of NtsR $1^{\mathrm{NEO}-\mathrm{Cre}}$;GFP mice (Fig. $2 \mathrm{~B}$ ) or NtsR2 $2^{\mathrm{NEO}-\mathrm{Cre}}$;GFP mice (data not shown). Taken together, these controls verify that GFP expression in our models is explicitly Cre dependent. Hence, any GFP observed in our studies is specifically due to Cre-mediated recombination in NtsR1 or NtsR2 cells, and can be trusted to identify them.

We next used the dual recombinase mouse models that we generated to visualize the distributions of NtsR1- and NtsR2-expressing cells in the VTA, and also whether they differed between developmental and adult stages. First, analysis of $N t s R 1^{D e v}$;GFP mice revealed a wide-spread, dense population of GFP + neurons in the VTA (Fig. 2C) and throughout the brain (data not shown). Despite many GFP-labeled neurons, we ruled out the possibility of ectopic expression via lack of GFP in regions that are thought to have minimal NtsR1 expression at any point in life, including the ip (Geisler et al., 2006; see ip in Fig. 2C). By contrast, NtsR1 $1^{\text {Adult }}$; GFP mice had far fewer GFP+ neurons that were primarily restricted to the VTA (Fig. 2D) and SN (data not shown). These findings are consistent with previous work showing that central NtsR1 expression peaks during gestation, but subsequently decreases and only remains prominent in select regions, including the VTA (Palacios et al., 1988; Lépée-Lorgeoux et al., 1999).

Analysis of NtsR2-reporter mice revealed two morphologically distinct populations of GFP-labeled cells in the VTA. A few GFP + cells displayed clear neuronal features (Fig. 2E, white arrows) but the vast majority of GFPlabeled cells in both developmental and adult models were detected in cells with diffuse, stellate morphology indicative of glial cells (Fig. 2E). This finding supports previous work suggesting that NtsR2 is expressed on astrocytes (Nouel et al., 1997, 1999; Yamauchi et al., 2007; Woodworth et al., 2017a). GFP-expressing cells with neuronal morphology were sparse in both $N t s R 2^{D e v}$; GFP and NtsR2 $2^{\text {Adult }}$;GFP models but slightly more of these putative neurons were detected in NtsR2 ${ }^{D e v}$;GFP mice (Fig. 2E,F). When quantified, we found that developmental NtsR1-GFP+ neurons outnumber NtsR2-GFP+ neurons $\sim 18-1$ (Fig. 2G; Table 1). While the total number of NtsR1-GFP+ neurons in the adult model is about half of that observed in the developmental model, adult NtsR1-GFP + neurons outnumber NtsR2-GFP+ neurons by 60-1 (Fig. 2H; Table 1). Collectively, these data indicate that NtsR1 is the predominant isoform expressed on VTA neurons in development and adulthood, while NtsR2 is primarily expressed on cells with glial morphology. Furthermore, our findings reveal that many cells express NtsR1 and NtsR2 at some stage of development, but in the adult brain NtsR1 expression is confined to a subset of VTA cells.

\section{Glial and neuronal markers distinguish NtsR1 and NtsR2 cells in the VTA}

Given the largely dissimilar morphologies of NtsR1GFP + and NtsR2-GFP + cells (Fig. 2), we speculated that these cells might be differentially classed as glia or neurons. To address this we examined VTA sections from the adult and developmental mouse models via immunofluorescence for S100 (a glial marker) and NeuN (a neuronal maker). We observed that GFP + cells in NtsR1 ${ }^{D e v}$;GFP mice and $N$ ts $R 1^{\text {Adult }}$;GFP mice were completely distinct from the $\mathrm{S} 100+$ glial cells (Fig. $3 A, B$ ). Conversely, most of the GFP + cells with diffuse, stellate morphology in $N$ tsR2 $2^{D e v}$;GFP mice and NtsR2 $2^{\text {Adult }}$;GFP mice overlapped with the $\mathrm{S} 100+$ cells (Fig. $3 C, D$, yellow arrows), though we also observed spare GFP+ cells with neuronal morphology that did not contain S100 (Fig. 3C,D). These data suggest that the majority of NtsR2 cells throughout the lifespan are glial in nature. In contrast, essentially all of the GFP + cells from NtsR $1^{\text {Dev }}$;GFP mice and NtsR $1^{\text {Adult }}$;GFP mice colabeled with the neuronal marker NeuN (Fig. 4A, $B$, yellow arrows). Since NeuN specifically labels nuclei, the few NtsR1-GFP + cells apparently lacking NeuN could be due to imaging a plane either above or below the nucleus. We also noted VTA NeuN + cells that did not contain GFP, indicating that many, but not all, VTA neurons contain NtsR1 (Fig. 4A,B, magenta arrows). As expected based on our findings from Figure 3 , the majority of the glial GFP + cells in NtsR2 $2^{\text {Dev }}$;GFP mice and $N$ ts $R 2^{\text {Adult }}$;GFP mice did not contain NeuN (Fig. 4C,D). The few GFP+ cells with neuronal morphology in these NtsR2-reporter mice did contain NeuN (Fig. 4C, white arrows). In sum, these data confirm that the majority of NtsR2-expressing cells in the VTA are glia, but NtsR1-expressing cells comprise a subset of the total VTA neuronal population.

\section{NtsR1 is the predominant isoform on VTA DA neurons}

To define the neurochemical phenotype of NtsR1- and NtsR2-expressing neurons, we examined VTA sections from the adult and developmental mouse models via immunofluorescence for tyrosine hydroxylase $(\mathrm{TH})$, the rate-limiting enzyme in catecholamine synthesis and a 


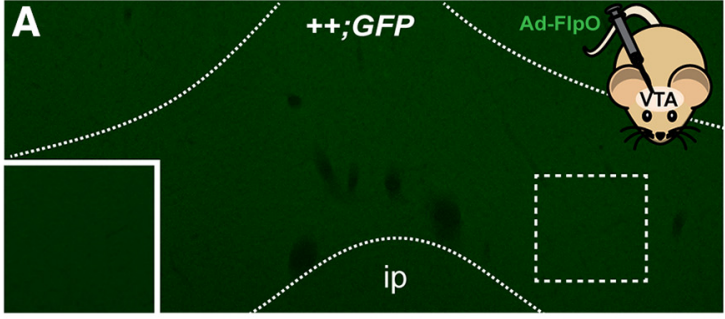

Developmental
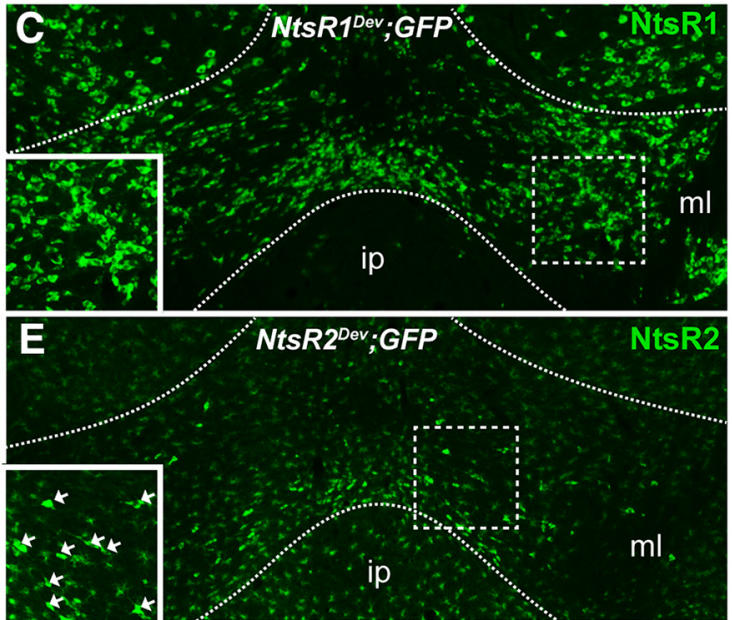

G

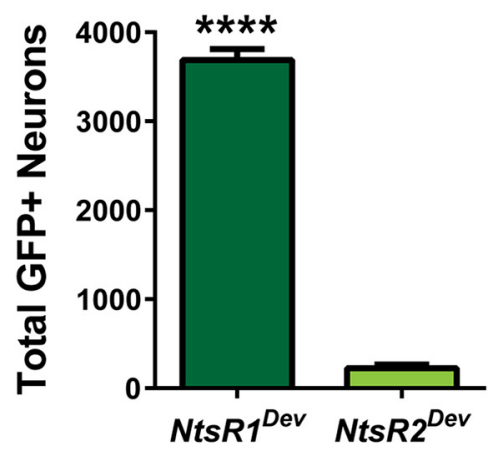

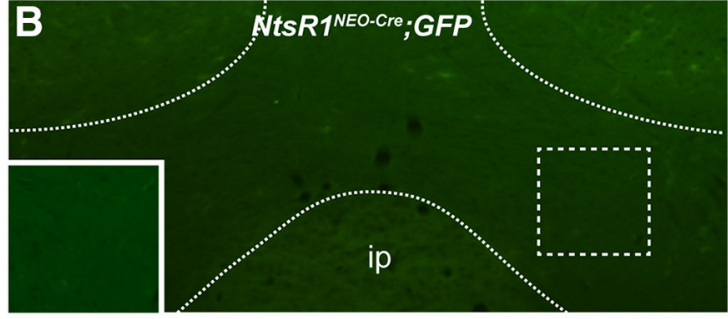

Adult
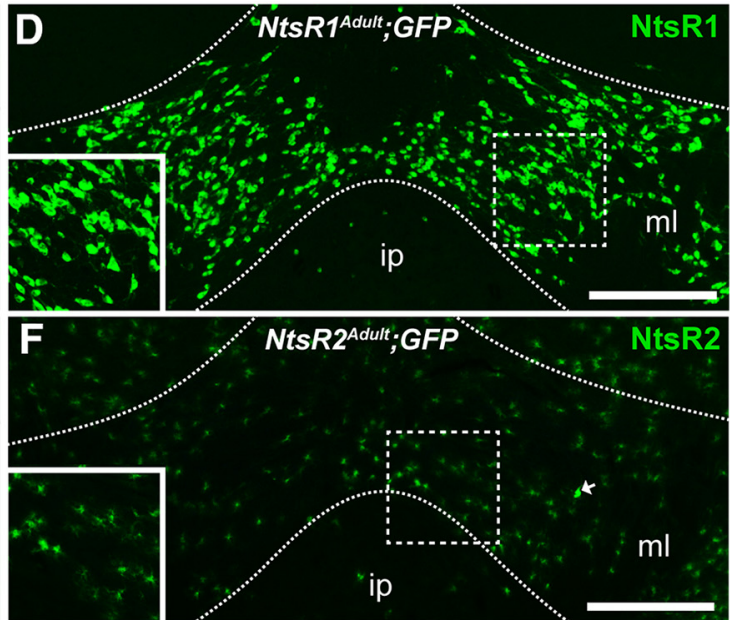

H

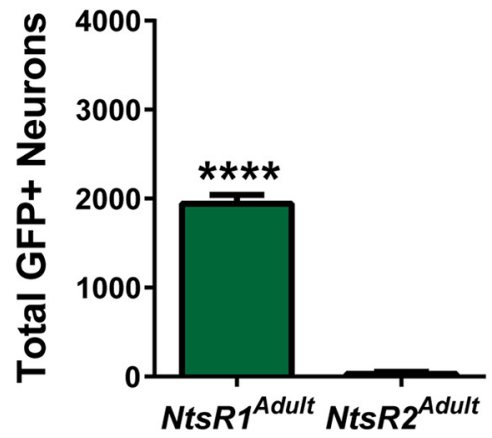

Figure 2. Developmental versus adult expression of NtsR1 and NtsR2 in the VTA. $\boldsymbol{A}$, No GFP is observed in the VTA of Rosa ${ }^{\text {eGFP-L10a }}$ reporter mice lacking Cre (++;GFP mice), even after Ad-FlpO injections, confirming that only Cre can drive GFP expression in this line. $B, N t s R 1^{N E O-C r e}$;GFP mice do not exhibit any GFP in the VTA, suggesting that the frt-flanked NEO cassette effectively blocks Cre expression and thus Cre-mediated GFP expression. $\boldsymbol{C}-\boldsymbol{H}, N t s R 1^{N E O-C r e}$ and $N t s R 2^{N E O-C r e}$ mice were bred to a Cre-inducible Rosa ${ }^{\text {eGFP-L10a }}$ reporter line and Cre expression was induced constitutively from conception (developmental expression) or only in adulthood. $\boldsymbol{C}, \boldsymbol{D}$, Developmental and adult distributions of NtsR1 cells. $\boldsymbol{E}, \boldsymbol{F}$, Developmental and adult distributions of NtsR2 cells. GFP + cells have either neuronal or glial morphology (white arrows). Images $\boldsymbol{A}-\boldsymbol{F}$ are shown at the same magnification, and scale bars represent $200 \mu \mathrm{m}$. Insets are digital enlargements of the areas within dashed boxes. $\boldsymbol{G}, \boldsymbol{H}$, Total number of GFP+ NtsR1 or NtsR2 neurons in developmental and adult models in the VTA $\left(N t s R 1^{\text {Dev }} n=3 ; N t s R 2^{\text {Dev }} n=3 ; N t s R 1^{\text {Adult }} n=3 ; N t s R 2^{\text {Adult }} n=6\right)$. Each bar represents mean \pm SEM, and data were analyzed by unpaired $t$ tests, $p<0.0001$ for both $\mathbf{G}_{\mathrm{a}}$ and $\mathbf{H}_{\mathrm{b}}$.

marker of DA neurons. This analysis revealed that nearly all ( 98\%) of VTA DA neurons express NtsR1 at some point in development (Fig. 5A,G; Table 1), while about two thirds ( $\sim 70 \%)$ of DA neurons actively coexpress NtsR1 in adulthood (Fig. 5B,H; Table 1). Interestingly, many THnegative VTA neurons coexpressed NtsR1 in the developmental model ( $\sim 30 \%$ of NtsR1-GFP+ neurons) but not the adult model (Fig. 5E,F; Table 1). Thus, during development NtsR1 is expressed in, and presumably regulates, both DA and other VTA neurons, but only mediates Nts actions in the adult brain via DA neurons.
By contrast, the majority of the small population of NtsR2-GFP + neurons in the developmental and adult models did not colocalize with TH (Fig. $5 C-F$ ) and NtsR2-GFP expression was found on only $6.5 \%$ of DA neurons in NtsR2 ${ }^{\text {Dev }}$; GFP mice and $<1 \%$ of DA neurons in NtsR2 ${ }^{\text {Adult }}$;GFP mice (Fig. 5G,H; Table 1). Taken together, these data support the hypothesis that NtsR1 is the dominant isoform regulating VTA DA neurons in both development and adulthood, and suggests that NtsR1 may also modulate non-DA neurons in the VTA during development. 


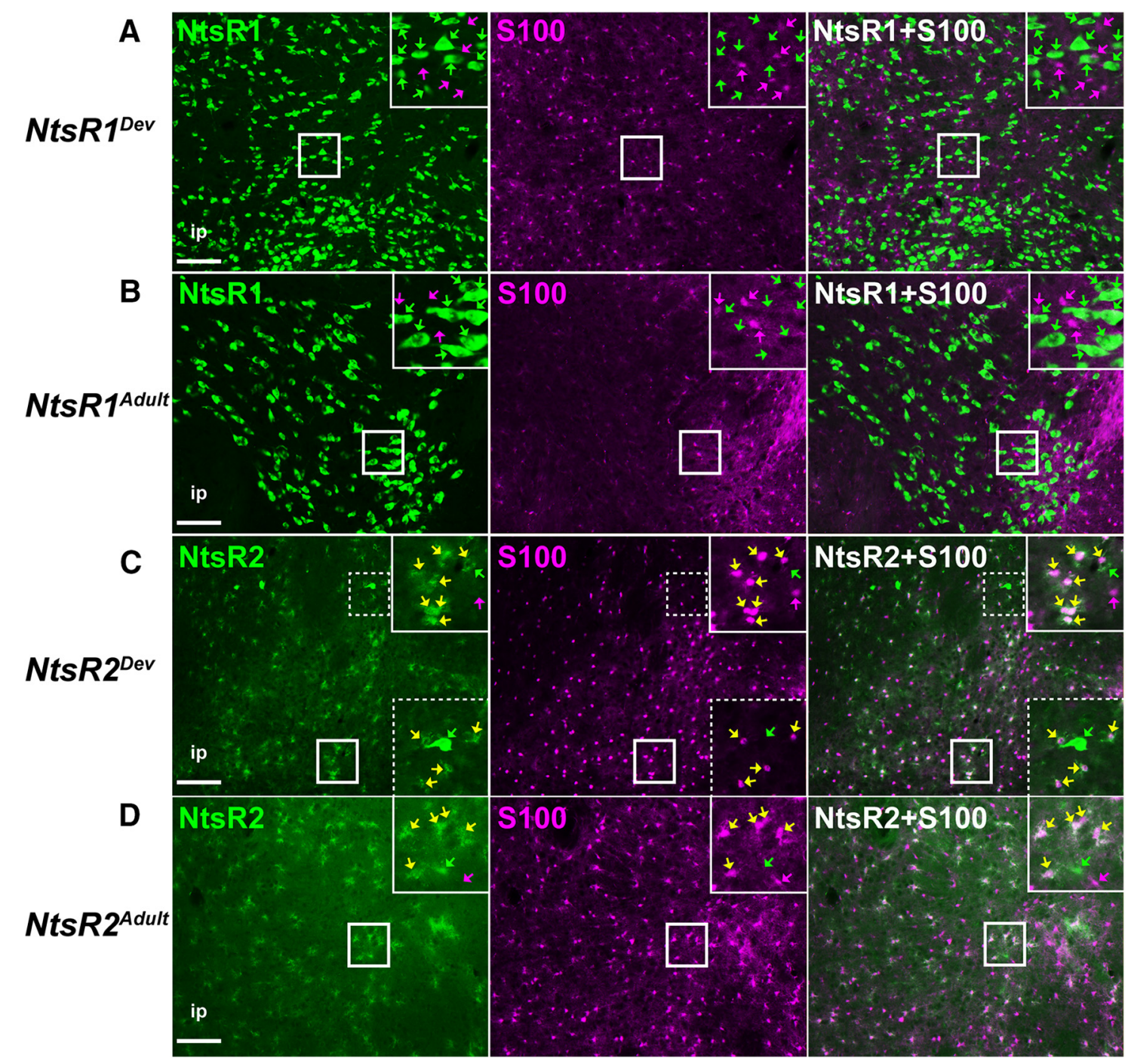

Figure 3. NtsR1 and NtsR2 colocalization with the glial marker S100 in development compared to adulthood. Representative images showing S100 coexpression in the VTA with $(\boldsymbol{A})$ developmental NtsR1-GFP + neurons, $(\boldsymbol{B})$ adult NtsR1-GFP + cells, $(\boldsymbol{C})$ developmental NtsR2-GFP + cells, amd $(\boldsymbol{D})$ adult NtsR2-GFP + cells. Yellow arrows: S100/GFP+ colocalized cells, indicating NtsR-containing cells that are glia; green arrows: GFP + only cells and magenta arrows $=\mathrm{S} 100+$ only cells. Scale bars: $100 \mu \mathrm{m}$. Insets are digital enlargements of the indicated boxed areas. NtsR $1^{\text {Dev }} n=3 ; N t s R 2^{D e v} n=3 ; N t s R 1^{\text {Adult }} n=3 ; N t s R 2^{\text {Adult }} n=3$.

\section{Projections of VTA NtsR1 neurons}

Given that NtsR1 was expressed on some, but not all VTA DA neurons in adult mice, we investigated whether NtsR1 defined the subset of VTA DA neurons that project to the nucleus accumbens (NA) or the prefrontal cortex (PFC; Swanson, 1982), the two major outputs of VTA DA neurons. To do this, we injected adult NtsR $1^{\triangle N E O-C r e}$;GFP mice in the VTA with the Cre-mediated tract tracer Adsyn-mCherry and examined brains 7-10 d later (Opland et al., 2013; Fig. 6A). In these brains GFP identifies any cell that expressed NtsR1 throughout lifespan, but only cells that actively express NtsR1 can undergo Cre-mediated recombination to express both GFP and the synaptophysin-mCherry fusion protein within cell bodies and terminals (Opland et al., 2013). Thus, this method allows us to discriminate cells that only expressed NtsR1 during development from the adult cells that currently express NtsR1 and can mediate DA release. Visualization of the
VTA revealed that nearly all mCherry + neurons coexpressed GFP; however, many GFP + neurons within the injection site did not coexpress mCherry (Fig. 6B, white arrows). These findings are consistent with our detection of almost twice as many NtsR1-GFP + neurons in $N$ tsR $1^{\text {Dev }}$;GFP mice compared to $N$ tsR $1^{\text {Adult }}$;GFP mice (Fig. 2E,F) and confirms that NtsR1 expression, and hence induction of Cre, is confined to a limited set of VTA neurons in the adult brain. Out of five injected mice, three had mCherry-labeling confined to the VTA and were used for analysis (Fig. 6C). We also injected Ad-syn-mCherry into the VTA of $N$ tsR $2^{\triangle N E O-C r e}$;GFP mice to verify the minor population NtsR2 neurons in the adult brain and define their projections. In contrast to the numerous mCherry-labeled neurons observed in NtsR $1^{\triangle N E O-C r e}$;GFP mice (Fig. $4 D$ ), examination of $N t s R 2^{\triangle N E O-C r e} ; G F P$ mice revealed very few mCherry + cells in the VTA. This small population of VTA NtsR2 neurons provided $<10$ single 


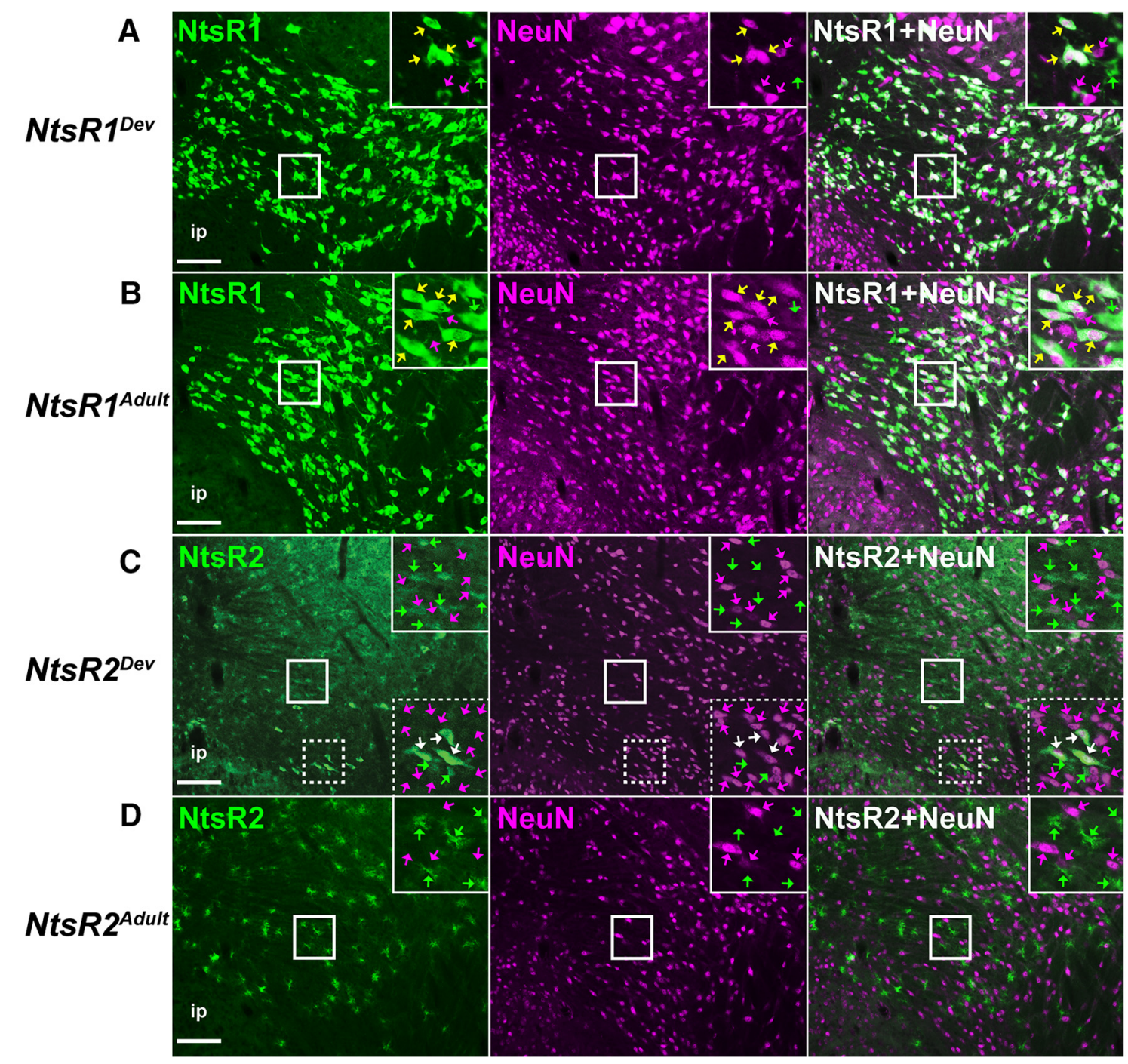

Figure 4. NtsR1 and NtsR2 colocalization with the neuronal marker NeuN in development compared to adulthood. Representative images showing NeuN coexpression in the VTA with $(\boldsymbol{A})$ developmental NtsR1-GFP+ cells, (B) adult NtsR1-GFP+ cells, (C) developmental NtsR2-GFP+ cells, and (D) adult NtsR2-GFP+ cells. Yellow arrows: NeuN/GFP+ colocalized cells that identify NtsR1 neurons; white arrows: NeuN/GFP + colocalized cells that identify the modest population of NtsR2 neurons in the VTA; green arrows: GFP + only cells and magenta arrows $=\mathrm{NeuN}+$ only neurons. Scale bars: $100 \mu \mathrm{m}$. Insets are digital enlargements of the indicated boxed areas. NtsR $1^{\text {Dev }} n=3 ; N t s R 2^{D e v} n=3 ; N t s R 1^{\text {Adult }} n=3 ; N t s R 2^{\text {Adult }} n=3$.

terminals observed throughout the entire brain, including a minor projection to the NA core (NAc) and the interstitial nucleus of the posterior limb of the anterior commissure (IPAC; Fig. 6E, white arrows). These data confirm the dearth of NtsR2-expressing neurons in the adult VTA (Fig. $2 F, H)$ and support a predominant role for NtsR1 in directly modifying VTA DA signaling.

We analyzed the projections from the well-targeted $N t s R 1^{\triangle N E O-C r e}$;GFP mice described in Figure 6, and these findings are summarized in Figure $7 M$. We note that our Ad-Syn-mCherry injections were biased to the lateral VTA, but also labeled mCherry + cell bodies within the medial VTA (Fig. 6C), which is known to contain DA neurons that project to the PFC or the NAc (Lammel et al., 2008). Thus, our acute anterograde tracer is appropriately positioned to identify any NtsR1 projections to the NA and PFC, if they exist. We found that VTA NtsR1 neurons most densely project to subregions of the ventral striatum, including the NAc, NA shell (NAsh), and olfactory tubercle (OFT; Fig. 7A-C). By contrast, the lack of terminals in the PFC implicates VTA NtsR1 neurons in regulating mesolimbic, but not mesocortical, DA signaling (Swanson, 1982). We also observed dense VTA NtsR1 terminals within the IPAC and modest terminals in the neighboring stria terminalis (ST; Fig. 7F). The caudate putamen (CPu) contained sparse VTA NtsR1 terminals (Fig. 7E), consistent with the VTA providing less input to the dorsal striatum compared to the SN (Bentivoglio et al., 1979; Swanson, 1982). A few mCherry-labeled terminals were observed in the ventral pallidum (VP; Fig. 7G) and the central amygdala $(\mathrm{CeA})$, where $\mathrm{DA}$ release is associated with emotional learning and feeding (Guarraci et al., 1999; Rosenkranz and Grace, 2002; Darvas et al., 2011; Anderberg et al., 2014). While we detected few terminals within 


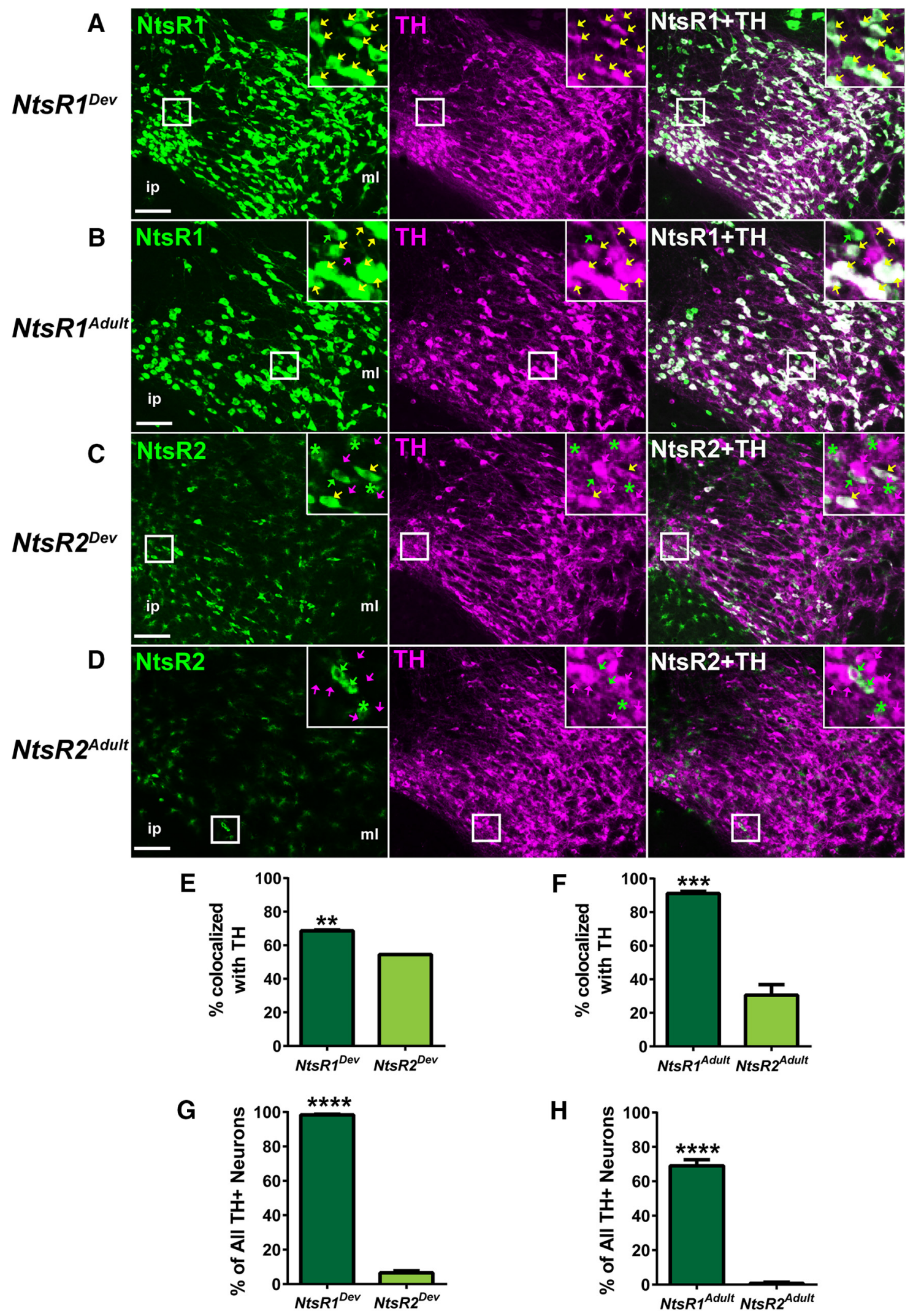

Figure 5. NtsR1 and NtsR2 colocalization with $\mathrm{TH}$ in development compared to adulthood. Representative images showing TH coexpression in the VTA with $(\boldsymbol{A})$ developmental NtsR1-GFP+ neurons, $(\boldsymbol{B})$ adult NtsR1-GFP+ neurons, (C) developmental NtsR2GFP + cells, and $(\boldsymbol{D})$ adult NtsR2-GFP + cells. Yellow arrows: TH/GFP + colocalized neurons; green arrows: GFP + only neurons; magenta arrows: TH+ only neurons; green asterisks: GFP+ glia. Scale bars: $100 \mu \mathrm{m}$. Insets are digital enlargements of the indicated 
continued

boxed areas. Percentage of NtsR1 and NtsR2 neurons that colocalize with TH in $(\boldsymbol{E})$ developmental $\left(p=0.0081_{\mathrm{c}}\right)$ and $(\boldsymbol{F})$ adult expression models $\left(p=0.0003_{d}\right)$. Percentage of all VTA TH+ neurons that colocalize with NtsR1 or NtsR2 in (G) developmental ( $p$

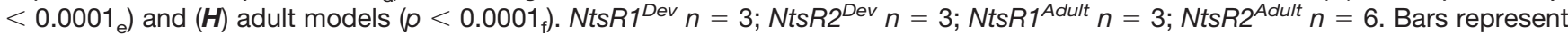
mean \pm SEM, and data were analyzed by unpaired $t$ tests.

the lateral hypothalamus (LHA), the dense patch of $m$ Cherry + fibers in the neighboring nigrostriatal tract (ns) likely represents VTA NtsR 1 axons traversing the brain en route to the striatum (Fig. $7 \mathrm{~J}$, see ns). Intriguingly, the lateral habenula (LHb) also contained many mCherrylabeled terminals (Fig. 7I), although VTA neurons projecting to the $\mathrm{LHb}$ do not release DA and instead inhibit the $\mathrm{LHb}$ to indirectly promote reward (Stamatakis et al., 2013). We also observed low to medium terminal density in the hindbrain, namely in the laterodorsal tegmental nucleus (LDTg; Fig. 7K), the parabrachial nucleus (PBN; Fig. $7 L$ ), and the dorsal raphe (DR; Fig. 7M).

Our acute anterograde tract tracing suggested that VTA NtsR1 neurons are mesolimbic, but not mesocortical, based on the presence of projections to the ventral striatum and their absence within the PFC. This finding could also result from a technical artifact, for example, if there was insufficient duration of mCherry-tracer expression necessary to label weak and/or far-projecting terminals. While we have previously found that the Ad-Syn-mCherry tracer provides robust projection labeling $10 \mathrm{~d}$ postinjection (Opland et al., 2013; Brown, 2017; Woodworth et al., 2017a), we also tested whether longer expression time might identify any VTA NtsR1 projections to the distant PFC. To do this we injected NtsR $1^{\text {Cre }}$ mice $(n=3)$ with Ad-Syn-mCherry and assessed expression four weeks later. This paradigm labeled numerous mCherry+ NtsR1 neurons within the medial and lateral VTA (Fig. 8A), which provide significant projections the NAc, but not to the PFC (Fig. 8B,C). These data suggest that the absence of NtsR1 projections to the PFC is not due to insufficient duration of mCherry-tracer expression necessary to label PFC projections and favor the interpretation that VTA NtsR1 neurons are primarily mesolimbic rather than mesocortical.

\section{Discussion}

Here, we used dual recombinase knock-in mice to identify NtsR1 and NtsR2 cells in the VTA to establish the precise cellular mediators of Nts action. We demonstrate that NtsR2 is predominately expressed on glial cells and only a small number of both DA and non-DAergic neurons throughout life. By contrast, NtsR1 is expressed on many VTA DA neurons during both development and adulthood. Furthermore, adult VTA NtsR1 neurons project to the ventral striatum, not the PFC, and hence are positioned to specifically modify mesolimbic DA signaling. Thus, our data demonstrate NtsR1 as the predominant receptor isoform by which $\mathrm{Nts}$ can directly engage DA neurons in the adult brain to modify DA-dependent signaling and physiology.

Previously, NtsR expression was characterized using $\mathrm{ISH}$, which labels mRNA but does not always provide sufficient signal to visualize the morphologic features of the cell in which it is expressed. An advantage of the dual recombinase strategy we used to identify NtsR-expressing cells is that Cre-induced GFP fills the entire cell, which allowed us to clearly distinguish between neuronal and glial morphologies. We were thus able to discern that most NtsR2 is expressed by glial cells throughout the brain, consistent with the diffuse, low intensity signal observed via ISH for Ntsr2 (Mazella et al., 1996; Sarret et al., 1998; Walker et al., 1998; Asselin et al., 2001). Similarly, cultured astrocytes express NtsR2 (Nouel et al., 1997, 1999; Yamauchi et al., 2007) and Nts modulates their activity (Hösli et al., 1995; Trudeau, 2000). Interestingly, because astrocytes also express endopeptidases that catabolize Nts (Woulfe et al., 1992; Mentlein and Dahms, 1994; Vincent et al., 1994), they might act as a sink to externalize and degrade residual $\mathrm{Nts}$ at the synapse via NtsR2. Loss of NtsR2 signaling, as in NtsR2-null mice, could lead to excess synaptic Nts and enhanced Nts-NtsR1 activation of VTA DA neurons, which may explain their increased striatal DA levels and hyperactivity (Liang et al., 2010).

Our findings provide cellular resolution that will be essential to understand how Nts mechanistically acts in the VTA. Consistent with our finding of NtsR1 expression on some VTA DA neurons, the application of Nts or Nts analogues into the VTA activates DA neurons, increases NA DA release, restrains food intake, and promotes reward behaviors, and these effects are reduced by NtsR1 antagonists or developmental deletion of NtsR1 (Remaury et al., 2002; Leonetti et al., 2004; Kim et al., 2008; Kempadoo et al., 2013; Rouibi et al., 2015). Similarly, Bose et al. (2015) suggested that Nts enhances excitatory input onto VTA DA neurons via NtsR1. However, not all studies using pharmacological agents or receptor null mice have supported a predominant role for NtsR1 in directly modulating VTA DA signaling. For example, Kempadoo et al., found that low doses of intra-VTA Nts increased excitatory transmission to DA neurons via NtsR1, while high doses of Nts reduced excitatory input through an NtsR1independent mechanism, implying involvement of NtsR2 (Kempadoo et al., 2013). Similarly, Rouibi et al., reported that Nts action in the VTA reduces excitatory input to DA neurons via an NtsR1-independent mechanism, again suggesting involvement of NtsR2 (Rouibi et al., 2015). Our finding that $<1 \%$ of adult VTA DA neurons coexpress NtsR2 suggest it is unlikely that Nts directly modulates most DA neurons via NtsR2. Furthermore, while NtsR2 is expressed on some non DAergic neurons in the adult brain, the overall number is low, which would make them challenging to find using electrophysiology. One possible mechanism to resolve these discrepancies arises from our finding that NtsR2 is predominantly expressed on glial 
A

NtsR1 $^{\triangle N E O-C r e} ;$ GFP<smiles>CCC12CC=C3CC(CC(C3)C1)C2</smiles>

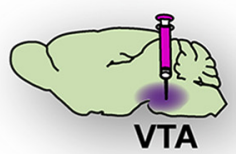

Stereotaxic Injection of Adenoviral-Syn-mCherry

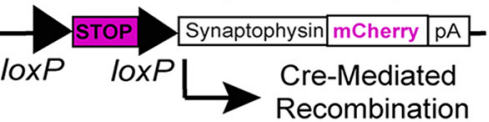

Ad-Syn-mCherry labels cell bodies and presynaptic terminals of VTA NtsR1 neurons

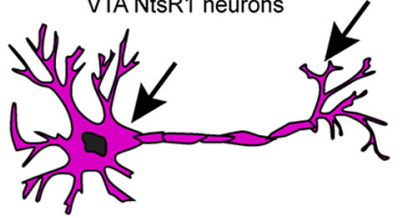

VTA NtsR1 Neuron
B

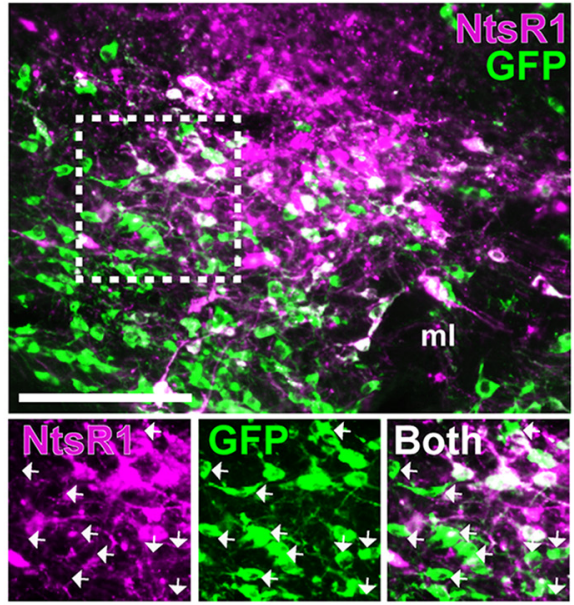

C
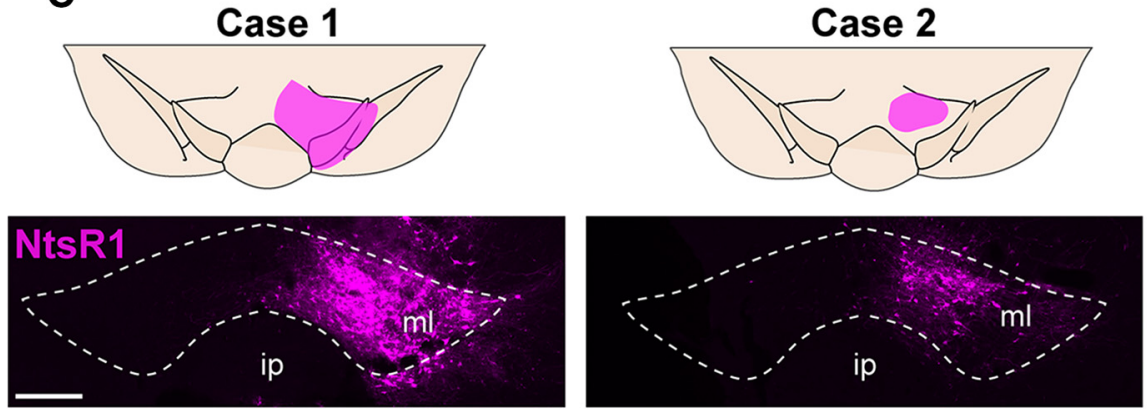

Case 2

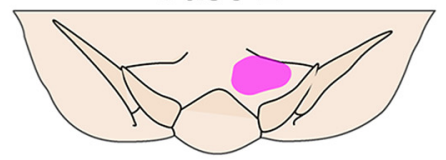

\section{Case 3}

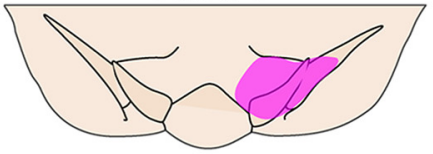

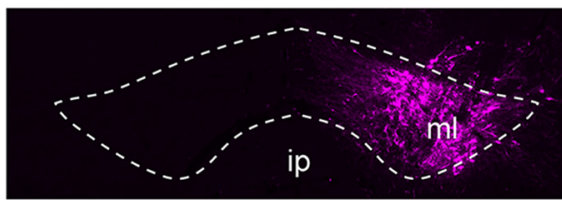

IPAC
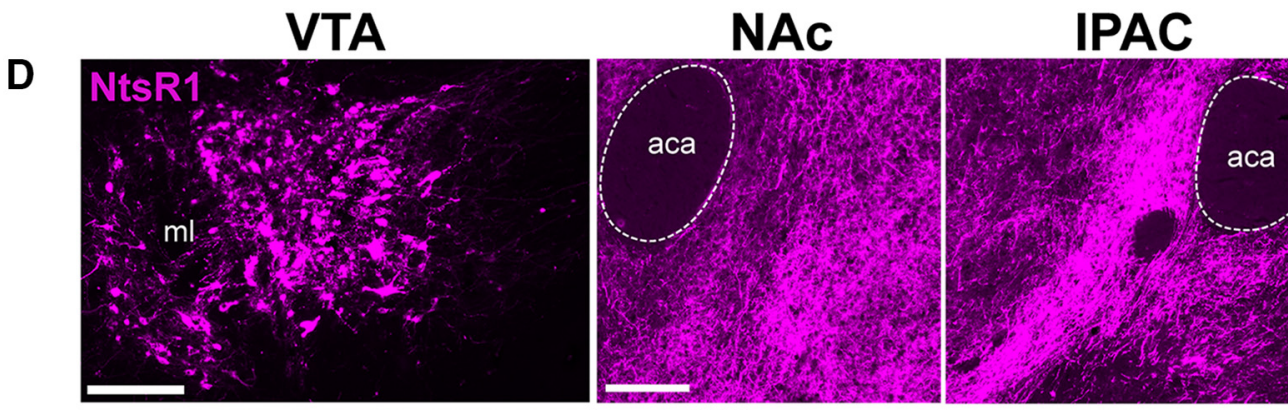

E
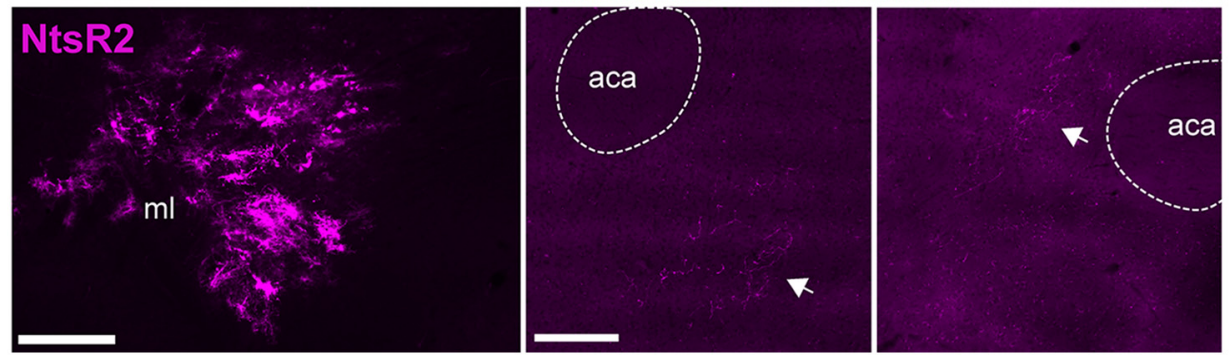

Figure 6. Ad-Syn-mCherry reveals projections of VTA NtsR1 neurons. $\boldsymbol{A}$, Schematic showing NtsR ${ }^{\triangle N E O-C r e}$;GFP mice injected in the VTA with Ad-Syn-mCherry, which labels VTA NtsR1 projections by expression of a Cre-inducible synaptophysin-mCherry fusion protein. B, VTA of NtsR1 ${ }^{\Delta N E O-C r e}$;GFP mouse injected with Ad-Syn-mCherry for 7-10 d showing GFP + neurons that do not coexpress mCherry (white arrows), representing neurons that transiently expressed NtsR1 during development. $\boldsymbol{C}$, Distribution of $\mathrm{mCherry}+$ cell bodies within the VTA from 3 individual NtsR1 $\triangle N E O-C r e ; G F P$ mice 7-10 d after Ad-syn-mCherry injection, confirming selective labeling of VTA NtsR1 neurons. Comparison of VTA injection site and mCherry-labeled terminals in the NAC and IPAC of (D) NtsR1 ${ }^{\Delta N E O-C r e}$; GFP mice versus $(E) N t s R 2^{\triangle N E O-C r e} ;$ GFP mice. Scale bars: $100 \mu \mathrm{m}$. aca, anterior commissure. 

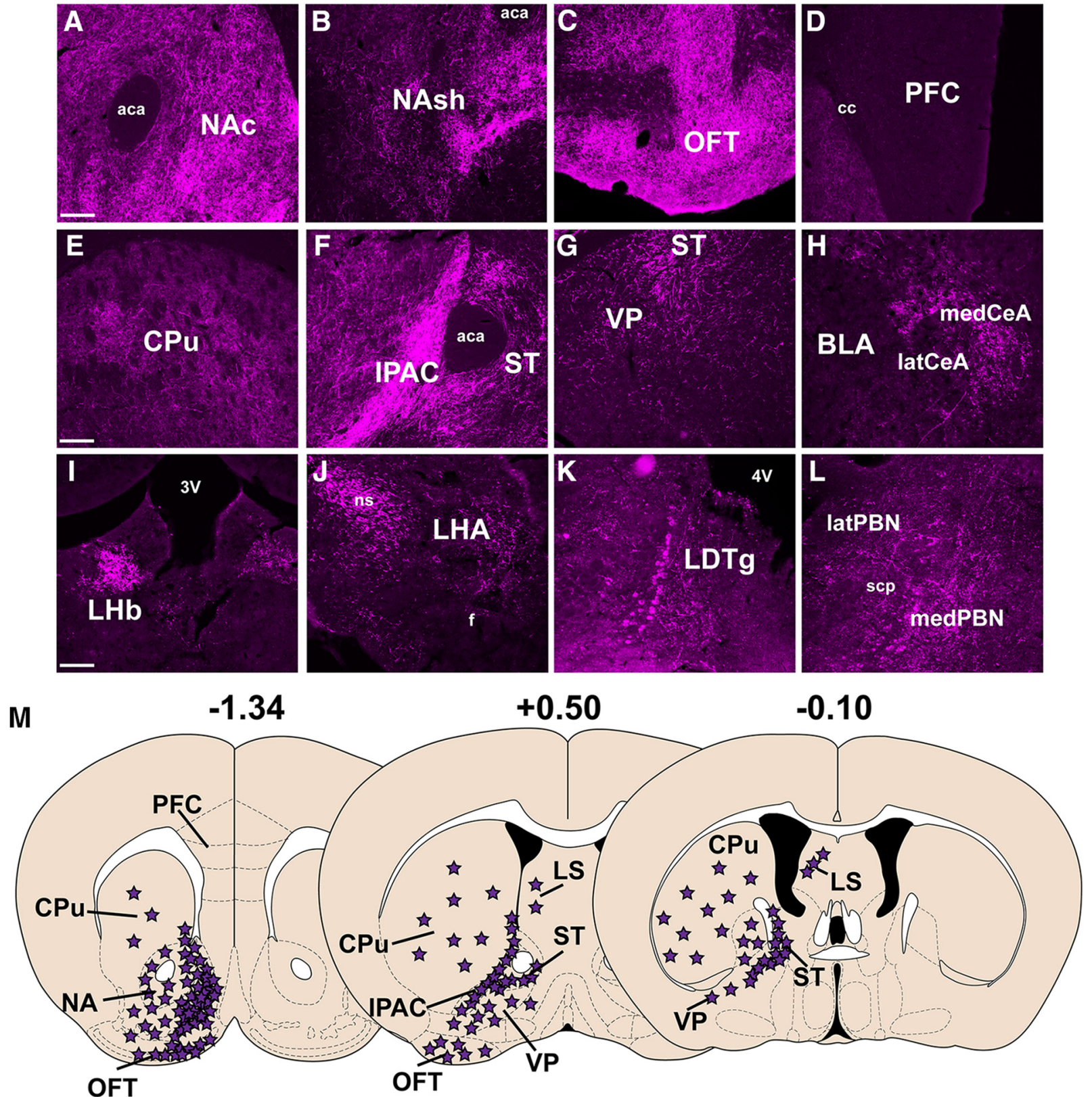

$+0.50$

$-0.10$
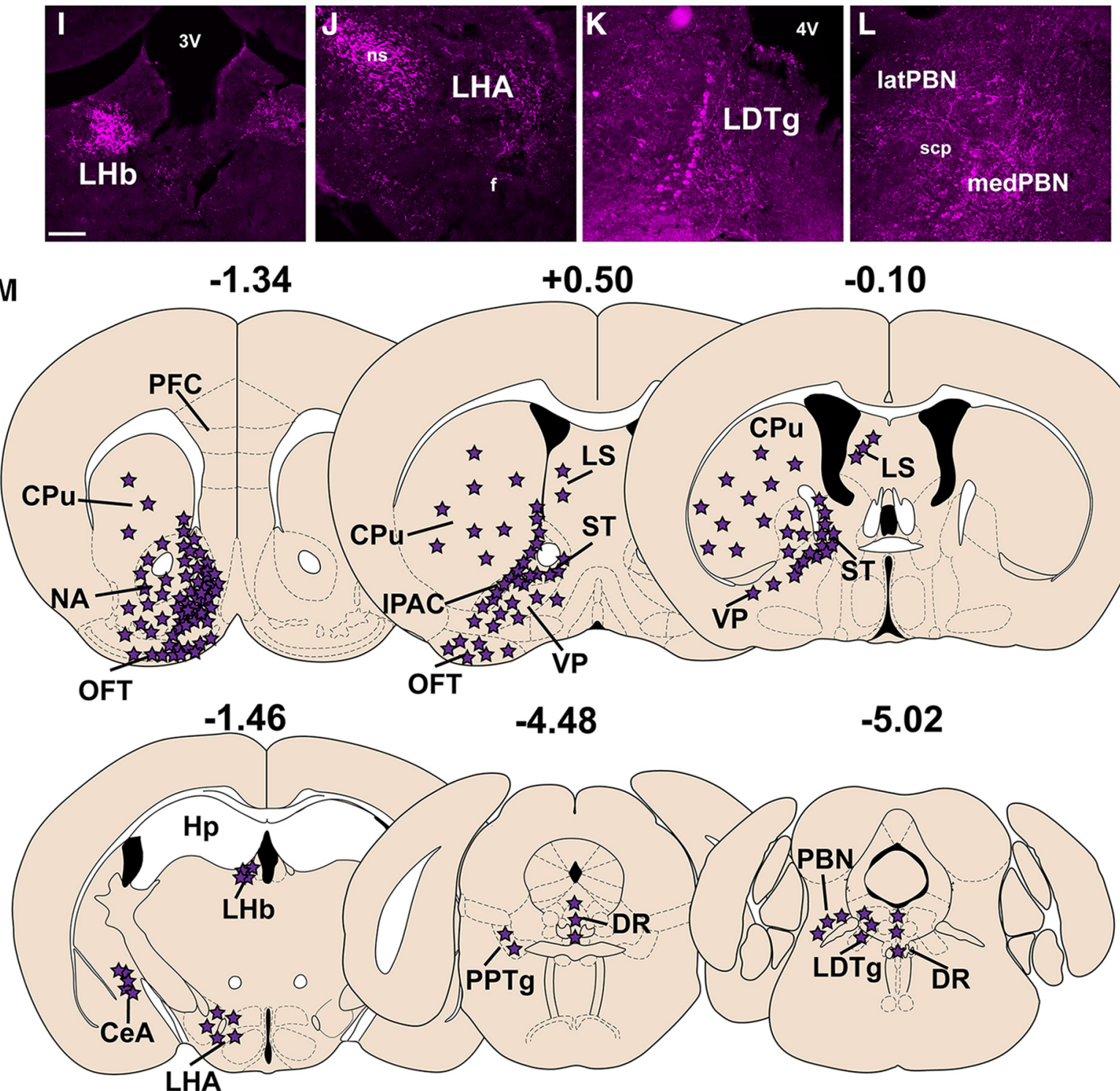

Figure 7. Projections of VTA NtsR1 neurons via acute projection labeling. Distribution of Ad-syn-mCherry-labeled terminals from the 7-10 D-injected mice described in Figure 6. Syn-mCherry-labeled terminals were observed in the (A) NAc, (B) NAsh, (C) OFT, (D)

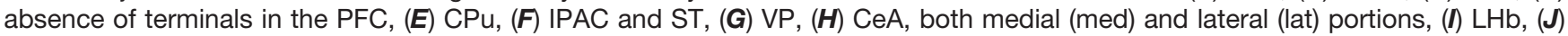
LHA, $(\boldsymbol{K})$ LDTg, and $(\boldsymbol{L})$ the medial and lateral portions of the PBN (medPBN and latPBN). $\boldsymbol{M}$, Schematic summarizing projections of 
continued

VTA NtsR1 neurons (purple stars). Scale bars: $100 \mu \mathrm{m}$. aca, anterior commissure; cc, corpus callous; BLA, basolateral amygdala; 3V, third ventricle; f, fornix; $4 \mathrm{~V}$, fourth ventricle; scp, superior cerebellar peduncle.

cells, which might act via tripartite synapses to mediate local regulation of DA neurons (Perea et al., 2009). Going forward, the ability to identify NtsR1 and NtsR2 cells will permit direct testing of how Nts engages these cells to orchestrate DA signaling.

While NtsR1 is robustly expressed on VTA DA neurons throughout life, our NtsR1 ${ }^{N E O-C r e} ;$ GFP models do not distinguish between neurons that express NtsR1 on the soma/dendrites versus synaptic terminals. The subcellular localization of NtsR1 is functionally important because Nts-NtsR1 signaling elicits different behavioral effects via either pre- or postsynaptic mechanisms. Nts-NtsR1 signaling on DA cell bodies in the VTA increases DA release and locomotor activity similar to psychostimulants (Kalivas et al., 1983; Kalivas and Duffy, 1990; Steinberg et al., 1994; Sotty et al., 2000; Legault et al., 2002; St-Gelais et al., 2004). By contrast, Nts-NtsR1 action in the NA suppresses locomotor activity induced by AMPH, cocaine, and DA itself, similar to antipsychotic medications (Ervin et al., 1981; Kalivas et al., 1984; Robledo et al., 1993), and is thought to be mediated by NtsR1 expressed presynaptically on DA terminals in the striatum. Studies using immunohistochemistry and autoradiography suggest that NtsR1 binding sites are present on DA terminals in the ventral and dorsal striatum (Quirion et al., 1985; Dilts and Kalivas, 1989; Schotte and Leysen, 1989). Furthermore, radiolabeled Nts injected in to the striatum accumulates in the cell bodies of VTA DA neurons (Castel et al., 1990, 1992; Faure et al., 1995), suggesting that Nts binds DA neurons at presynaptic terminals and is internalized. Collectively, VTA Nts-NtsR1 signaling appears to have opposing behavioral outcomes depending on whether it occurs pre- or postsynaptically, and this should be taken into account when interpreting future data from $N$ ts $R 1^{N E O-}$ cre mice.

VTA DA neurons are heterogeneous and have been defined by their projection targets (Juarez and Han, 2016; Morales and Margolis, 2017). We found that adult VTA NtsR1 neurons comprise $\sim 70 \%$ of VTA DA neurons and project primarily to the NA, OFT, and IPAC, but not to other efferent targets of VTA NA neurons such as the PFC or hippocampus (Swanson, 1982). Given that many VTA NtsR1 neurons are mesolimbic, they are likely to modulate the reinforcing properties of natural and pharmacologic rewards, which depend on DA release to the NA (Fiorillo et al., 2003; Rutledge et al., 2010; Lammel et al., 2011, 2012; Hart et al., 2014). Furthermore, our current data provides a cellular and circuit mechanism to explain how Nts signaling directly via VTA NtsR1 neurons can increase NA DA release and mediate conditioned reward (Kalivas et al., 1983; Glimcher et al., 1984, 1987; Sotty et al., 2000; Legault et al., 2002; St-Gelais et al., 2004; Kempadoo et al., 2013; Rouibi et al., 2015). Overall, VTA NtsR1 neurons project to regions that can modify reward intake, suggesting that Nts action via the VTA is necessary for the drive for pharmacological and natural rewards, such as food and social interaction. The functional implications of the VTA NtsR1 projections to regions other than the ventral striatum are less clear, but will be important to investigate in the future.

A limitation of the developmental NtsR $1^{\triangle N E O-C r e} ; G F P$ and $N t s R 2^{\Delta N E O-C r e} ;$ GFP models we developed is that GFP expression does not necessarily reflect cells with active NtsR1 or NtsR2 expression. Inducing Cre expression from the beginning of embryonic development in the developmental models leads to permanent GFP expression in all cells that expressed NtsR1 or NtsR2 at any point in life. Comparing findings from developmental to adult models however, can inform how NtsR expression patterns change through life. For example, essentially all VTA DA neurons colocalize with GFP in NtsR1 ${ }^{\text {Dev }}$;GFP mice whereas only $\sim 70 \%$ colocalize in NtsR1 ${ }^{\text {Adult }}$; GFP mice. These data imply that at some point in development $\sim 30 \%$ of DA neurons transiently expressed NtsR1, but do not identify when they cease expressing NtsR1. Inducing FlpO expression at discrete time points across development will be required to define the temporal dynamics of NtsR1 expression. This could be accomplished by breeding mice to a tamoxifen-inducible FlpO deleter line, whereby injection of tamoxifen would induce Cre expression at any desired point in development (Lao et al., 2012) to label cells actively expressing NtsR1.
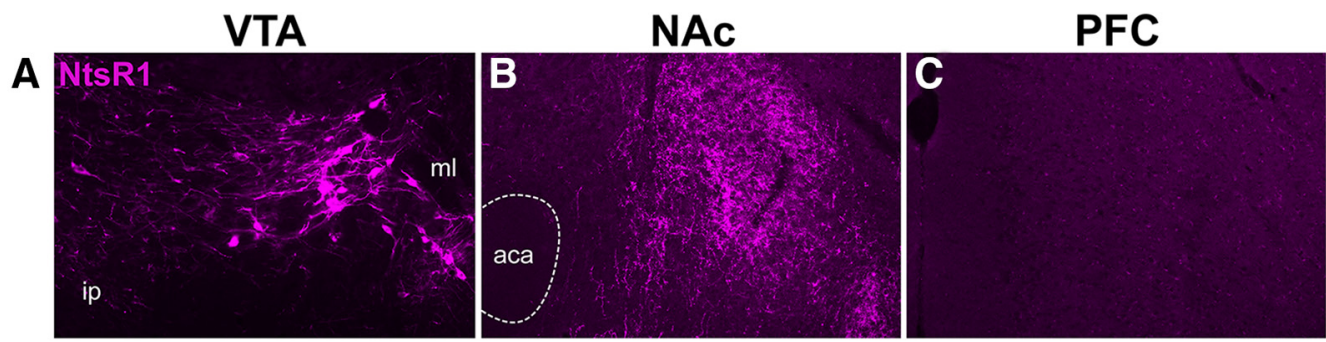

Figure 8. Extended expression of anterograde tract tracer in VTA NtsR1 neurons. NtsR1 ${ }^{\Delta N E O-C r e}$;GFP mice were injected in the VTA with Ad-Syn-mCherry $(n=3)$ and mCherry labeling was assessed four weeks later. $\boldsymbol{A}$, This extended vector expression time resulted in mCherry labeling of VTA NtsR1 cell bodies and (B) numerous projections to the NAc, $(\boldsymbol{C})$ but not to the PFC. aca, anterior commissure. 
Our work indicates vast expression of NtsR1 throughout the brain in NtsR1 $1^{D e v}$;GFP mice, and a heretofore unappreciated potential role for Nts to mediate development of the central nervous system. Within the VTA, NtsR ${ }^{\text {Dev }}$;GFP mice showed nearly $100 \%$ of VTA DA neurons colocalizing with GFP, which represented $\sim 65 \%$ of all GFP+ neurons. Curiously, this is similar to the overall distribution of DA and non-DA neurons in adults ( $65 \%$ $\mathrm{TH}+, 35 \% \mathrm{TH}-$; Morales and Margolis, 2017) and suggests that at some point in life almost every VTA neuron, both DA and non-DAergic, expresses NtsR1. Nts-NtsR1 signaling may thus play a critical role in establishing VTA circuits during development. Mice null for NtsR1 may therefore suffer from abnormal formation of the VTA DA system that causes aberrant DA signaling, locomotor activity, body weight, anxiety, sleep, and exaggerated response to psychostimulants that has been reported to occur in this line (Remaury et al., 2002; Li et al., 2010; Liang et al., 2010; Fitzpatrick et al., 2012; Opland et al., 2013). Our data also identify a substantial population of VTA NtsR1 neurons that persist in the adult brain, and hence signify roles for Nts signaling via NtsR1 in regulating normal physiology. Going forward, using NtsR $1^{N E O-C r e}$ mice will permit selective manipulation of the VTA NtsR1 neurons in the adult brain to discern how they contribute to DA signaling, physiology, and behavior.

\section{References}

Alexander MJ, Leeman SE (1998) Widespread expression in adult rat forebrain of mRNA encoding high-affinity neurotensin receptor. $J$ Comp Neur 402:475-500. Medline

Anderberg RH, Anefors C, Bergquist F, Nissbrandt H, Skibicka KP (2014) Dopamine signaling in the amygdala, increased by food ingestion and GLP-1, regulates feeding behavior. Physiol Behav 136:135-144. CrossRef Medline

Asselin ML, Dubuc I, Coquerel A, Costentin J (2001) Localization of neurotensin NTS2 receptors in rat brain, using. Neuroreport 12: 1087-1091. Medline

Bentivoglio M, van der Kooy D, Kuypers HG (1979) The organization of the efferent projections of the substantia nigra in the rat. $A$ retrograde fluorescent double labeling study. Brain Res 174:1-17. CrossRef

Bissette G, Luttinger D, Mason GA, Hernandez DE, Loosen PT (1982) Neurotensin and thermoregulation. Ann NY Acad Sci 400:268282. Medline

Bose P, Rompré PP, Warren RA (2015) Neurotensin enhances glutamatergic EPSCs in VTA neurons by acting on different neurotensin receptors. Peptides 73:43-50. CrossRef Medline

Botto JM, Guillemare E, Vincent JP, Mazella J (1997) Effects of SR 48692 on neurotensin-induced calcium-activated chloride currents in the Xenopus oocyte expression system: agonist-like activity on the levocabastine-sensitive neurotensin receptor and absence of antagonist effect on the levocabastine insensitive neurotensin receptor. Neurosci Lett 223:193-196. Medline

Boules MM, Fredrickson P, Muehlmann AM, Richelson E (2014) Elucidating the role of neurotensin in the pathophysiology and management of major mental disorders. Behav Sci (Basel) 4:125153. CrossRef

Cáceda R, Kinkead B, Nemeroff CB (2006) Neurotensin: role in psychiatric and neurological diseases. Peptides 27:2385-2404. CrossRef Medline

Castel MN, Malgouris C, Blanchard JC, Laduron PM (1990) Retrograde axonal transport of neurotensin in the dopaminergic nigrostriatal pathway in the rat. Neuroscience 36:425-430. Medline
Castel MN, Woulfe J, Wang X, Laduron PM, Beaudet A (1992) Light and electron microscopic localization of retrogradely transported neurotensin in rat nigrostriatal dopaminergic neurons. Neuroscience 50:269-282. Medline

Chalon P, Vita N, Kaghad M, Guillemot M, Bonnin J, Delpech B, Le Fur G, Ferrara P, Caput D (1996) Molecular cloning of a levocabastine-sensitive neurotensin binding site. FEBS Lett 386: 91-94. CrossRef

Darvas M, Fadok JP, Palmiter RD (2011) Requirement of dopamine signaling in the amygdala and striatum for learning and maintenance of a conditioned avoidance response. Learn Mem 18:136143. CrossRef

Dilts RP, Kalivas PW (1989) Autoradiographic localization of muopioid and neurotensin receptors within the mesolimbic dopamine system. Brain Res 488:311-327. CrossRef

Ervin GN, Birkemo LS, Nemeroff CB, Prange AJ Jr (1981) Neurotensin blocks certain amphetamine-induced behaviours. Nature 291: 73-76. CrossRef

Faure MP, Nouel D, Beaudet A (1995) Axonal and dendritic transport of internalized neurotensin in rat mesostriatal dopaminergic neurons. Neuroscience 68:519-529. Medline

Fiorillo CD, Tobler PN, Schultz W (2003) Discrete coding of reward probability and uncertainty by dopamine neurons. Science 299: 1898-1902. CrossRef

Fitzpatrick K, Winrow CJ, Gotter AL, Millstein J, Arbuzova J, Brunner J, Kasarskis A, Vitaterna MH, Renger JJ, Turek FW (2012) Altered sleep and affect in the neurotensin receptor 1 knockout mouse. Sleep 35:949-956. CrossRef Medline

Geisler S, Bérod A, Zahm DS, Rostene W (2006) Brain neurotensin, psychostimulants, and stress-emphasis on neuroanatomical substrates. Peptides 27:2364-2384. CrossRef Medline

Ghodsi A, Stein C, Derksen T, Martins I, Anderson R, Davidson B (1999) Systemic hyper- osmolality improves b-glucuronidase distribution and pathology in murine MPS VII brain following intraventricular gene transfer. Exp Neurol 160:109-116. CrossRef

Gholizadeh S, Tharmalingam S, Macaldaz ME, Hampson DR (2013) Transduction of the central nervous system after intracerebroventricular injection of adeno-associated viral vectors in neonatal and juvenile mice. Hum Gene Ther Methods 24:205-213. CrossRef Medline

Glimcher PW, Margolin DH, Giovino AA, Hoebel BG (1984) Neurotensin: a new 'reward peptide'. Brain Res 291:119-124. Medline

Glimcher PW, Giovino AA, Hoebel BG (1987) Neurotensin selfinjection in the ventral tegmental area. Brain Res 403:147-150. Medline

Guarraci FA, Frohardt RJ, Young SL, Kapp BS (1999) A functional role for dopamine transmission in the amygdala during conditioned fear. Ann NY Acad Sci 877:732-736. Medline

Hart AS, Rutledge RB, Glimcher PW, Phillips PE (2014) Phasic dopamine release in the rat nucleus accumbens symmetrically encodes a reward prediction error term. J Neurosci 34:698-704. CrossRef

Hösli E, Stauffer S, Hösli L (1995) Autoradiographic and electrophysiological evidence for the existence of neurotensin receptors on cultured astrocytes. Neuroscience 66:627-633. Medline

Juarez B, Han MH (2016) Diversity of dopaminergic neural circuits in response to drug exposure. Neuropsychopharmacology 41:24242446. CrossRef

Kalivas PW, Duffy P (1990) Effect of acute and daily neurotensin and enkephalin treatments on extracellular dopamine in the nucleus accumbens. J Neurosci 10:2940-2949.

Kalivas PW, Burgess SK, Nemeroff CB, Prange AJ Jr (1983) Behavioral and neurochemical effects of neurotensin microinjection into the ventral tegmental area of the rat. Neuroscience 8:495-505. CrossRef

Kalivas PW, Nemeroff CB, Prange AJ Jr (1984) Neurotensin microinjection into the nucleus accumbens antagonizes dopamineinduced increase in locomotion and rearing. Neuroscience 11: 919-930. CrossRef 
Kempadoo KA, Tourino C, Cho SL, Magnani F, Leinninger GM, Stuber GD, Zhang F, Myers MG, Deisseroth K, de Lecea L, Bonci A (2013) Hypothalamic neurotensin projections promote reward by enhancing glutamate transmission in the VTA. J Neurosci 33: 7618-7626. CrossRef

Kim ER, Leckstrom A, Mizuno TM (2008) Impaired anorectic effect of leptin in neurotensin receptor 1-deficient mice. Behav Brain Res 194:66-71. CrossRef Medline

Kleczkowska P, Lipkowski AW (2013) Neurotensin and neurotensin receptors: characteristic, structure-activity relationship and pain modulation-a review. Eur J Pharmacol 716:54-60. CrossRef

Krashes MJ, Koda S, Ye C, Rogan SC, Adams AC, Cusher DS, Maratos-Flier E, Roth BL, Lowell BB (2011) Rapid, reversible activation of AgRP neurons drives feeding behavior in mice. $\mathrm{J}$ Clin Invest 121:1424-1428. CrossRef Medline

Krashes MJ, Shah BP, Madara JC, Olson DP, Strochlic DE, Garfield AS, Vong L, Pei H, Watabe-Uchida M, Uchida N, Liberles SD, Lowell BB (2014) An excitatory paraventricular nucleus to AgRP neuron circuit that drives hunger. Nature 507:238-242. CrossRef Medline

Lammel S, Hetzel A, Häckel O, Jones I, Liss B, Roeper J (2008) Unique properties of mesoprefrontal neurons with a dual mesocorticolimbic dopamine system. Neuron 57:760-773. CrossRef Medline

Lammel S, Ion DI, Roeper J, Malenka RC (2011) Projection-specific modulation of dopamine neuron synapses by aversive and rewarding stimuli. Neuron 70:855-862. CrossRef Medline

Lammel S, Lim BK, Ran C, Huang KW, Betley MJ, Tye KM, Deisseroth K, Malenka RC (2012) Input-specific control of reward and aversion in the ventral tegmental area. Nature 491:212-217. CrossRef Medline

Lao Z, Raju GP, Bai CB, Joyner AL (2012) MASTR: a technique for mosaic mutant analysis with spatial and temporal control of recombination using conditional floxed alleles in mice. Cell Rep 2:386-396. CrossRef Medline

Legault M, Congar P, Michel FJ, Trudeau LE (2002) Presynaptic action of neurotensin on cultured ventral tegmental area dopaminergic neurones. Neuroscience 111:177-187. Medline

Lein ES, Hawrylycz MJ, Ao N, Ayres M, Bensinger A, Bernard A, Boe AF, Boguski MS, Brockway KS, Byrnes EJ, Chen L, Chen L, Chen TM, Chin MC, Chong J, Crook BE, Czaplinska A, Dang CN, Datta S, Dee NR, et al. (2007) Genome-wide atlas of gene expression in the adult mouse brain. Nature 445:168-176. CrossRef Medline

Leinninger GM, Opland DM, Jo YH, Faouzi M, Christensen L, Cappellucci LA, Rhodes CJ, Gnegy ME, Becker JB, Pothos EN, Seasholtz AF, Thompson RC, Myers MG Jr (2011) Leptin action via neurotensin neurons controls orexin, the mesolimbic dopamine system and energy balance. Cell Metab 14:313-323. CrossRe

Leonetti M, Brun P, Clerget M, Steinberg R, Soubrié P, Renaud B, Suaud-Chagny MF (2004) Specific involvement of neurotensin type 1 receptor in the neurotensin-mediated in vivo dopamine efflux using knock-out mice. J Neurochem 89:1-6. CrossRef Medline

Lépée-Lorgeoux I, Betancur C, Rostène W, Pélaprat D (1999) Differential ontogenetic patterns of levocabastine-sensitive neurotensin NT2 receptors and of NT1 receptors in the rat brain revealed by in situ hybridization. Brain Res Dev Brain Res 113:115-131. CrossRef

Li Z, Liang Y, Boules M, Gordillo A, Richelson E (2010) Effect of amphetamine on extracellular concentrations of amino acids in striatum in neurotensin subtype 1 and 2 receptor null mice: a possible interaction between neurotensin receptors and amino acid systems for study of schizophrenia. Neuropharmacology 58: 1174-1178. CrossRef Medline

Liang Y, Boules M, Li Z, Williams K, Miura T, Oliveros A, Richelson E (2010) Hyperactivity of the dopaminergic system in NTS1 and NTS2 null mice. Neuropharmacology 58:1199-1205. CrossRef Medline

Maeno H, Yamada K, Santo-Yamada Y, Aoki K, Sun YJ, Sato E, Fukushima T, Ogura H, Araki T, Kamichi S, Kimura I, Yamano M,
Maeno-Hikichi Y, Watase K, Aoki S, Kiyama H, Wada E, Wada K (2004) Comparison of mice deficient in the high- or low-affinity neurotensin receptors, Ntsr1 or Ntsr2, reveals a novel function for Ntsr2 in thermal nociception. Brain Res 998:122-129. Medline

Mazella J, Botto JM, Guillemare E, Coppola T, Sarret P, Vincent JP (1996) Structure, functional expression, and cerebral localization of the levocabastine-sensitive neurotensin/neuromedin $\mathrm{N}$ receptor from mouse brain. J Neurosci 16:5613-5620. Medline

Mazella J, Zsürger N, Navarro V, Chabry J, Kaghad M, Caput D, Ferrara P, Vita N, Gully D, Maffrand JP, Vincent JP (1998) The $100-\mathrm{kDa}$ neurotensin receptor is gp95/sortilin, a non-G-proteincoupled receptor. J Biol Chem 273:26273-26276. Medline

Mentlein R, Dahms P (1994) Endopeptidases 24.16 and 24.15 are responsible for the degradation of somatostatin, neurotensin, and other neuropeptides by cultivated rat cortical astrocytes. J Neurochem 62:27-36. Medline

Morales M, Margolis EB (2017) Ventral tegmental area: cellular heterogeneity, connectivity and behaviour. Nat Rev Neurosci 18:7385. CrossRef Medline

Nicot A, Rostene W, Berod A (1994) Neurotensin receptor expression in the rat forebrain and midbrain: a combined analysis by in situ hybridization and receptor autoradiography. J Comp Neur 341: 407-419. CrossRef Medline

Nouel D, Faure MP, St Pierre JA, Alonso R, Quirion R, Beaudet A (1997) Differential binding profile and internalization process of neurotensin via neuronal and glial receptors. J Neurosci 17:17951803.

Nouel D, Sarret P, Vincent JP, Mazella J, Beaudet A (1999) Pharmacological, molecular and functional characterization of glial neurotensin receptors. Neuroscience 94:1189-1197. Medline

Opland D, Sutton A, Woodworth H, Brown J, Bugescu R, Garcia A, Christensen L, Rhodes C, Myers M Jr, Leinninger G (2013) Loss of neurotensin receptor-1 disrupts the control of the mesolimbic dopamine system by leptin and promotes hedonic feeding and obesity. Mol Metab 2:423-434. CrossRef

Palacios JM, Pazos A, Dietl MM, Schlumpf M, Lichtensteiger W (1988) The ontogeny of brain neurotensin receptors studied by autoradiography. Neuroscience 25:307-317. Medline

Paxinos G., Franklin B (2001) The Mouse Brain in Stereotaxic Coordinates. San Diego, CA, Academic Press.

Perea G, Navarrete M, Araque A (2009) Tripartite synapses: astrocytes process and control synaptic information. Trends Neurosci 32:421-431. CrossRef Medline

Pettibone DJ, Hess JF, Hey PJ, Jacobson MA, Leviten M, Lis EV, Mallorga PJ, Pascarella DM, Snyder MA, Williams JB, Zeng Z (2002) The effects of deleting the mouse neurotensin receptor NTR1 on central and peripheral responses to neurotensin. J Pharmacol Exp Ther 300:305-313. Medline

Quirion R, Chiueh CC, Everist HD, Pert A (1985) Comparative localization of neurotensin receptors on nigrostriatal and mesolimbic dopaminergic terminals. Brain Res 327:385-389. CrossRef

Remaury A, Vita N, Gendreau S, Jung M, Arnone M, Poncelet M, Culouscou JM, Le Fur G, Soubrié P, Caput D, Shire D, Kopf M, Ferrara $P$ (2002) Targeted inactivation of the neurotensin type 1 receptor reveals its role in body temperature control and feeding behavior but not in analgesia. Brain Res 953:63-72. CrossRef

Robledo P, Maldonado R, Koob GF (1993) Neurotensin injected into the nucleus accumbens blocks the psychostimulant effects of cocaine but does not attenuate cocaine self-administration in the rat. Brain Res 622:105-112. CrossRef

Rosenkranz JA, Grace AA (2002) Dopamine-mediated modulation of odour-evoked amygdala potentials during Pavlovian conditioning. Nature 417:282-287. CrossRef Medline

Rouibi K, Bose P, Rompré PP, Warren RA (2015) Ventral midbrain NTS1 receptors mediate conditioned reward induced by the neurotensin analog, D-Tyr[11]neurotensin. Front Neurosci 9:470. CrossRef Medline

Roussy G, Beaudry H, Lafrance M, Belleville K, Beaudet N, Wada K, Gendron L, Sarret P (2010) Altered morphine-induced analgesia in 
neurotensin type 1 receptor null mice. Neuroscience 170:12861294. CrossRef Medline

Rutledge RB, Dean M, Caplin A, Glimcher PW (2010) Testing the reward prediction error hypothesis with an axiomatic model. $\mathrm{J}$ Neurosci 30:13525-13536. CrossRef

Sarret P, Beaudet A, Vincent JP, Mazella J (1998) Regional and cellular distribution of low affinity neurotensin receptor mRNA in adult and developing mouse brain. J Comp Neur 394:344-356. Medline

Sarret P, Perron A, Stroh T, Beaudet A (2003) Immunohistochemical distribution of NTS2 neurotensin receptors in the rat central nervous system. J Comp Neur 461:520-538. CrossRef Medline

Schotte A, Leysen JE (1989) Autoradiographic evidence for the localization of high affinity neurotensin binding sites on dopaminergic nerve terminals in the nigrostriatal and mesolimbic pathways in rat brain. J Chem Neuroanat 2:253-257. Medline

Schroeder LE, Leinninger GM (2017) Role of central neurotensin in regulating feeding: implications for the development and treatment of body weight disorders. Biochim Biophys Acta 1864:900-916.

Soliman GA, Ishida-Takahashi R, Gong Y, Jones JC, Leshan RL, Saunders TL, Fingar DC, Myers MG Jr (2007) A simple qPCRbased method to detect correct insertion of homologous targeting vectors in murine ES cells. Transgenic Res 16:665-670. CrossRef

Sotty F, Brun P, Leonetti M, Steinberg R, Soubrié P, Renaud B, Suaud-Chagny MF (2000) Comparative effects of neurotensin, neurotensin(8-13) and [D-Tyr(11)]neurotensin applied into the ventral tegmental area on extracellular dopamine in the rat prefrontal cortex and nucleus accumbens. Neuroscience 98:485-492. CrossRef

St-Gelais F, Legault M, Bourque MJ, Rompré PP, Trudeau LE (2004) Role of calcium in neurotensin-evoked enhancement in firing in mesencephalic dopamine neurons. J Neurosci 24:2566-2574. CrossRef

Stamatakis AM, Jennings JH, Ung RL, Blair GA, Weinberg RJ, Neve RL, Boyce F, Mattis J, Ramakrishnan C, Deisseroth K, Stuber GD (2013) A unique population of ventral tegmental area neurons inhibits the lateral habenula to promote reward. Neuron 80:10391053. CrossRef Medline

Steinberg R, Brun P, Fournier M, Souilhac J, Rodier D, Mons G, Terranova JP, Le Fur G, Soubrié P (1994) SR 48692, a non-peptide neurotensin receptor antagonist differentially affects neurotensininduced behaviour and changes in dopaminergic transmission. Neuroscience 59:921-929. Medline

Swanson LW (1982) The projections of the ventral tegmental area and adjacent regions: a combined fluorescent retrograde tracer and immunofluorescence study in the rat. Brain Res Bull 9:321353. CrossRef

Tanaka K, Masu M, Nakanishi S (1990) Structure and functional expression of the cloned rat neurotensin receptor. Neuron 4:847854. Medline
Thomas JB, Vivancos M, Giddings AM, Wiethe RW, Warner KR, Murza A, Besserer-Offroy E, Longpré JM, Runyon SP, Decker AM, Gilmour BP, Sarret P (2016) Identification of 2-(\{[1-(4-fluorophenyl)5-(2-methoxyphenyl)-1H-pyrazol-3-yl]carbonyl\}amino)tricyclo[3.3.1.13,7] decane-2-carboxylic acid (NTRC-844) as a selective antagonist for the rat neurotensin receptor type 2. ACS Chem Neurosci 7:1225-1231. CrossRef

Trudeau LE (2000) Neurotensin regulates intracellular calcium in ventral tegmental area astrocytes: evidence for the involvement of multiple receptors. Neuroscience 97:293-302. Medline

Vincent B, Vincent JP, Checler F (1994) Neurotensin and neuromedin $\mathrm{N}$ undergo distinct catabolic processes in murine astrocytes and primary cultured neurons. Eur J Biochem 221:297-306. Medline

Vita N, Laurent P, Lefort S, Chalon P, Dumont X, Kaghad M, Gully D, Le Fur G, Ferrara P, Caput D (1993) Cloning and expression of a complementary DNA encoding a high affinity human neurotensin receptor. FEBS Lett 317:139-142. CrossRef

Vita N, Oury-Donat F, Chalon P, Guillemot M, Kaghad M, Bachy A, Thurneyssen O, Garcia S, Poinot-Chazel C, Casellas P, Keane P, Le Fur G, Maffrand JP, Soubrie P, Caput D, Ferrara P (1998) Neurotensin is an antagonist of the human neurotensin NT2 receptor expressed in Chinese hamster ovary cells. Eur J Pharmacol 360:265-272. CrossRef

Vong L, Ye C, Yang Z, Choi B, Chua S, Jr, Lowell BB (2011) Leptin action on GABAergic neurons prevents obesity and reduces inhibitory tone to POMC neurons. Neuron 71:142-154. CrossRef

Walker N, Lepee-Lorgeoux I, Fournier J, Betancur C, Rostene W, Ferrara P, Caput D (1998) Tissue distribution and cellular localization of the levocabastine-sensitive neurotensin receptor mRNA in adult rat brain. Brain Res Mol Brain Res 57:193-200. Medline

Woodworth H, Batchelor H, Beekly B, Bugescu R, Brown J, Kurt G, Fuller P, Leinninger G (2017a) Neurotensin receptor-1 identifies a subset of ventral tegmental dopamine neurons that coordinates energy balance. Cell Rep 20:1881-1892.

Woodworth H, Beekly B, Batchelor H, Bugescu R, Perez-Bonilla P, Schroeder L, Leinninger G (2017b) Lateral hypothalamic neurotensin neurons orchestrate dual weight loss behaviors via distinct mechanisms. Cell Rep 21:3116-3128.

Woulfe J, Checler F, Beaudet A (1992) Light and electron microscopic localization of the neutral metalloendopeptidase EC 3.4.24.16 in the mesencephalon of the rat. Eur J Neurosci 4:13091319. CrossRef

Yamada M, Yamada M, Lombet A, Forgez P, Rostène W (1998) Distinct functional characteristics of levocabastine sensitive rat neurotensin NT2 receptor expressed in Chinese hamster ovary cells. Life Sciences 62:PL 375-380. CrossRef

Yamauchi R, Wada E, Kamichi S, Yamada D, Maeno H, Delawary M, Nakazawa T, Yamamoto T, Wada K (2007) Neurotensin type 2 receptor is involved in fear memory in mice. J Neurochem 102: 1669-1676. CrossRef Medline 